\title{
Climatology of Upper Tropospheric-Lower Stratospheric (UTLS) Jets and Tropopauses in MERRA
}

\author{
GLORIA L. MANNEY \\ NorthWest Research Associates, and New Mexico Institute of Mining and Technology, Socorro, New Mexico \\ Michaela I. HegGLiN \\ University of Reading, Reading, United Kingdom \\ William H. Daffer, Michael J. Schwartz, Michelle L. Santee \\ Jet Propulsion Laboratory, California Institute of Technology, Pasadena, California \\ STEVEN PAWSON \\ NASA Goddard Space Flight Center, Greenbelt, Maryland
}

(Manuscript received 24 April 2013, in final form 20 September 2013)

\begin{abstract}
A global climatology (1979-2012) from the Modern-Era Retrospective Analysis for Research and Applications (MERRA) shows distributions and seasonal evolution of upper tropospheric jets and their relationships to the stratospheric subvortex and multiple tropopauses. The overall climatological patterns of upper tropospheric jets confirm those seen in previous studies, indicating accurate representation of jet stream dynamics in MERRA. The analysis shows a Northern Hemisphere (NH) upper tropospheric jet stretching nearly zonally from the mid-Atlantic across Africa and Asia. In winter-spring, this jet splits over the eastern Pacific, merges again over eastern North America, and then shifts poleward over the North Atlantic. The jets associated with tropical circulations are also captured, with upper tropospheric westerlies demarking cyclonic flow downstream from the Australian and Asian monsoon anticyclones and associated easterly jets. Multiple tropopauses associated with the thermal tropopause "break" commonly extend poleward from the subtropical upper tropospheric jet. In Southern Hemisphere $(\mathrm{SH})$ summer, the tropopause break, along with a poleward-stretching secondary tropopause, often occurs across the tropical westerly jet downstream of the Australian monsoon region. SH high-latitude multiple tropopauses, nearly ubiquitous in June-July, are associated with the unique polar winter thermal structure. High-latitude multiple tropopauses in NH fall-winter are, however, sometimes associated with poleward-shifted upper tropospheric jets. The SH subvortex jet extends down near the level of the subtropical jet core in winter and spring. Most SH subvortex jets merge with an upper tropospheric jet between May and December; although much less persistent than in the $\mathrm{SH}$, merged NH subvortex jets are common between November and April.
\end{abstract}

\section{Introduction}

Upper tropospheric jet streams have been recognized as a key component of the atmospheric circulation since their discovery in the late nineteenth century [e.g., see concise historical introductions in Koch et al. (2006)

Corresponding author address: Gloria L. Manney, Dept. of Physics, New Mexico Institute of Mining and Technology, Socorro, NM 87801.

E-mail: manney@nwra.com and Schiemann et al. (2009)]. They exhibit strong relationships to storm track dynamics, atmospheric blocking, Rossby wave propagation, and tropical convection (Wallace et al. 1988; Matthews and Kiladis 1999; Horinouchi et al. 2000; Chang et al. 2002; Nakamura and Shimpo 2004; Schwierz et al. 2004, and references therein). In particular, they are instrumental in guiding Rossby wave propagation (e.g., Martius et al. 2010), with consequences for extreme weather events (e.g., Schubert et al. 2011) and tropical/subtropical mixing via Rossby wave breaking (RWB) (e.g., Waugh and 
Polvani 2000). Their association with blocking events, which are implicated in triggering stratospheric sudden warmings (SSWs) (Martius et al. 2009; Nishii et al. 2011, and references therein), links them to the stratospheric circulation. Modeling and observational studies suggest a poleward shift of the upper tropospheric subtropical jet (thus widening the "tropical belt") resulting from the changing climate (e.g., Lorenz and DeWeaver 2007; Seidel et al. 2008; Strong and Davis 2007, 2008; Archer and Caldeira 2008; Davis and Rosenlof 2012).

The upper tropospheric jets and the stratospheric polar vortex and subvortex [the lowest portion of the polar vortex that may extend into the lowermost stratosphere, McIntyre (1995)] play an important role in coupling the stratospheric and tropospheric circulations. In addition to the upper tropospheric jets' role in forcing stratospheric disturbances, the structure of the stratospheric vortex is critical to wave coupling between the stratosphere and troposphere (e.g., Harnik et al. 2011). Climate model simulations indicate that the effects of the upper tropospheric-lower stratospheric (UTLS) jets on wave drag are key factors controlling the circulation response to greenhouse-gas-induced tropospheric warming (e.g., McLandress and Shepherd 2009; Sigmond and Scinocca 2010).

The jets are instrumental in organizing transport in the UTLS and thus in controlling extratropical stratospheretroposphere exchange (STE). The chemical composition of the UTLS is critical since radiative forcing of surface temperatures is most sensitive to ozone and water vapor changes near the tropopause (e.g., Lacis et al. 1990; Forster and Shine 1997; Solomon et al. 2010). The Antarctic ozone hole has caused significant lower stratospheric temperature and circulation changes (Polvani et al. 2011, and references therein), and substantial ozone depletion occurs in the lowermost stratosphere, where greater permeability of the subvortex transport barrier allows chemically processed air to be more efficiently transported to midlatitudes (e.g., Lee et al. 2002; Santee et al. 2011). Santee et al. (2011) showed that the top of an upper tropospheric jet may act as the primary transport barrier after the stratospheric polar night jet has eroded in the subvortex region. Model studies indicate a strong sensitivity of Southern Hemisphere (SH) UTLS jets to ozone depletion and recovery (e.g., Son et al. 2008; McLandress et al. 2011; Grise et al. 2013).

An abrupt drop in thermal tropopause height, or "tropopause break," from the equatorward to the poleward side of the subtropical upper tropospheric jet is a key climatological feature related to extratropical STE. Multiple tropopauses are often observed extending poleward from the tropopause break (e.g., Randel et al. 2007; Añel et al. 2008; Peevey et al. 2012) and have been associated with changes in UTLS composition through intrusions of tropospheric air above the primary tropopause (e.g., Pan et al. 2009; Homeyer et al. 2011). RWB is prevalent along the flanks of the upper tropospheric polar and subtropical westerly jets and the stratospheric polar night jet (e.g., Randel and Held 1991; Hitchman and Huesmann 2007; Isotta et al. 2008; Homeyer and Bowman 2013) and is associated with mixing and large-scale transport (e.g., Hegglin et al. 2005, 2009; Pan et al. 2009; Hitchman and Rogal 2010; Rogal et al. 2010; Homeyer et al. 2011). The vertical depth of the extratropical transition layer (the region with mixed tropospheric and stratospheric characteristics around the extratropical tropopause, e.g., Gettelman et al. 2011) is influenced by the contributions of RWB to both horizontal and vertical mixing (e.g., Hegglin et al. 2005; Konopka and Pan 2012).

In the zonal-mean perspective, the extratropical upper tropospheric jets comprise a "subtropical" or a "polar" westerly jet, or both. The polar jet is primarily "eddy driven," in contrast to the "radiatively driven" subtropical jet (e.g., Held and Phillips 1990; Lee and Kim 2003, and references therein). The subtropical jet is maintained through a balance between acceleration by the poleward flow in the Hadley cell and deceleration by Rossby waves propagating equatorward from midlatitudes; its latitude and strength are thus largely determined by the relative strength of thermal forcing and Rossby wave drag (e.g., Held and Hou 1980; Lee and Kim 2003; Son and Lee 2005). Eddy-zonal flow feedbacks related to RWB are important to "self-maintenance" of the eddy-driven polar jets (e.g., Lorenz and Hartmann 2003; Robinson 2006; Bordi et al. 2007; Garfinkel et al. 2013). Eddy-driven jet occurrence, latitude, and persistence are related to the distribution of wave activity and the position and strength of the subtropical jet (e.g., Lee and Kim 2003; Son and Lee 2005; Eichelberger and Hartmann 2007; Barnes and Hartmann 2011). When baroclinic eddies occur near the latitude of the subtropical jet (e.g., Grotjahn 1993), that jet may act as a waveguide on which those eddies propagate downstream; this wave activity may not thus result in a persistent eddy-driven jet (e.g., Eichelberger and Hartmann 2007; Barnes and Hartmann 2011). Lee and Kim (2003) point out that, in the observed zonally asymmetric flow, different manifestations of these mechanisms may occur at different times and longitudes; hybrid jets, driven by both thermal and eddy forcing, have also been reported (e.g., Lee and Kim 2003; Eichelberger and Hartmann 2007; Li and Wettstein 2012). Given the interplay between the mechanisms, a large degree of complexity in the spatial and temporal variations of upper tropospheric jets is expected when viewed in three dimensions. 
Several recent studies have explored aspects of the climatology of upper tropospheric jets using reanalysis data. Koch et al. (2006) used 15-yr European Centre for Medium-Range Weather Forecasts (ECMWF) ReAnalysis (ERA-15) data to develop an event-based global jet-stream climatology and compared the seasonal, primarily two-dimensional (2D), evolution in the two hemispheres. Strong and Davis $(2007,2008)$ used National Centers for Environmental Prediction (NCEP)National Center for Atmospheric Research (NCAR) and 40-yr ECMWF Re-Analysis (ERA-40) data to examine jet streams using a three-dimensional (3D) view for the Northern Hemisphere (NH) winter, reporting on their relationships to teleconnections and evidence for trends. Archer and Caldeira (2008) explored trends in jets using the NCEP-NCAR reanalysis in a global $2 \mathrm{D}$ view using a mass-weighted average throughout the upper troposphere. Barton and Ellis (2009) examined variability and trends in the North Pacific jet streams using NCEPNCAR reanalysis 300-hPa winds. Schiemann et al. (2009) extended the method of Koch et al. (2006) to 3D to explore the variability of and trends in the upper tropospheric jets in the Tibetan Plateau region. Limbach et al. (2012) developed a new four-dimensional event-tracking and identification algorithm and applied it to look at the climatology of upper tropospheric jets, especially merging and splitting events, in two years of operational ECMWF data. Several studies of the climatology of RWB (e.g., Waugh and Polvani 2000; Hitchman and Huesmann 2007; Isotta et al. 2008; Ndarana and Waugh 2011) and of multiple tropopauses (e.g., Randel et al. 2007; Añel et al. 2008) have been conducted. Both phenomena are related to the patterns of transport around the UTLS jets. The representation of the UTLS jets and tropopauses in the National Aeronautics and Space Administration Global Modeling and Assimilation Office (GMAO) Modern-Era Retrospective Analysis for Research and Applications (MERRA) has not been studied in detail.

Manney et al. (2011) described a method of characterizing the upper tropospheric jets, subvortex jets, and the tropopauses, and showed preliminary applications relating jet characteristics to UTLS trace-gas transport. In this study, their method is used to characterize the UTLS jet structures in MERRA and their relationship to the tropopause from 1979 through 2012. Section 2 briefly describes the MERRA dataset and the methods used. Sections 3 and 4 present the climatologies and annual cycle of the relationships between the upper tropospheric jets, the subvortex jet, and multiple tropopauses. Section 5 shows some climatological features of the jets and tropopauses in the jet-coordinate framework of Manney et al. (2011). A summary and conclusions are presented in section 6 .

\section{Data and analysis}

\section{a. MERRA reanalysis data}

The GEOS-5.2.0 general circulation model (GCM) and data assimilation system (DAS) used to produce the $\sim 34-y r$ MERRA record are described by Rienecker et al. (2008). Six-hourly meteorological analyses for Goddard Earth Observing System 5 (GEOS-5) are produced with the Gridpoint Statistical Interpolation (GSI) analysis method of Wu et al. (2002), which is a three-dimensional variational data assimilation (3D-Var) approach. The analyses include wind and temperature data from radiosondes and aircraft, as well as infrared and microwave radiances from a broad range of satellites, all of which directly impact the analyses in the UTLS (Rienecker et al. 2011). The fields used in this study are the $3 \mathrm{D}$ assimilated products from the DAS. These were computed using the GEOS-5 GCM with an additional forcing known as the incremental analysis update (IAU) computed from the difference between the model forecast and the analysis (Bloom et al. 1996). The IAU is the forcing needed to adjust the GCM state to the atmospheric analysis when applied as a time-invariant field over the 6-h duration of the forecast. Application of the IAU as a smooth forcing field leads to a smoothly evolving assimilated state, which is ideally suited to atmospheric transport studies. Ozone from the MERRA online analysis, which uses partial columns from the Solar Backscatter Ultraviolet (SBUV) instruments, is coupled to the meteorology via the radiative impacts on the GCM and the infrared satellite radiances used for temperature and moisture analyses, but infrared radiance observations have no impact on ozone and there are no covariance terms between ozone and the meteorological fields.

Most of the assimilated MERRA fields used in this work are archived at the full GCM resolution of $0.5^{\circ}$ latitude by $0.6667^{\circ}$ longitude, with 72 model levels from the surface to $0.01 \mathrm{hPa}$. The vertical grid spacing in the UTLS is about $1 \mathrm{~km}$, and this is expected to be the primary factor limiting the vertical resolution of the analyzed fields. MERRA potential vorticity (PV) was cataloged only on 42 pressure levels from 1000 to $0.1 \mathrm{hPa}$ on a reduced horizontal grid $\left(1.25^{\circ} \times 1.25^{\circ}\right)$. Because the jets and tropopauses are characterized on the full resolution grid, the PV fields are interpolated back to that grid. Comparisons of the jet and tropopause characterization done with MERRA versus operational GEOS-5 fields (for which the PV is provided on the model grid) show negligible differences in large-scale and climatological features, but "dynamical" tropopauses calculated from MERRA PV are substantially smoothed, often leading to distinctly different structures in individual 
daily fields in situations (such as in the vicinity of tropopause folds) where the tropopause varies rapidly.

\section{b. Jet and tropopause characterization}

The methods of Manney et al. (2011), used to characterize the jets and tropopauses, are summarized below. Figure 1 shows several examples of latitude-altitude wind speed sections illustrating the methodology, as well as showing typical synoptic patterns that give rise to climatological features discussed later in the paper.

At each longitude on the MERRA grid, upper tropospheric jet cores are identified in the vertical (latitudealtitude) cross section. Wind speed maxima at levels between 400 and $100 \mathrm{hPa}$ that exceed $40 \mathrm{~m} \mathrm{~s}^{-1}$ are identified as jet cores [marked "Sn" and "N $n$ " $(n=1,2, \ldots)$ in Fig. 1, with lowest numbers indicating strongest jets]. The boundary of the jet region around each core is defined by a wind speed of $30 \mathrm{~m} \mathrm{~s}^{-1}$. When more than one maximum above $40 \mathrm{~m} \mathrm{~s}^{-1}$ appears within a given $30 \mathrm{~m} \mathrm{~s}^{-1}$ contour, they are defined as separate cores if the latitudinal distance between them is greater than $15^{\circ}$ or the decrease in wind speed between them is greater than $25 \mathrm{~m} \mathrm{~s}^{-1}$ (e.g., S1 and S2 in Fig. 1b are separate, whereas of the three maxima exceeding $40 \mathrm{~m} \mathrm{~s}^{-1}$ near $30^{\circ} \mathrm{N}$ in Fig. 1a, only one, N2, is identified as the core in that region). These parameters were tuned to approximate the choices that would be made by visual inspection. The altitude and latitude, as well as dynamical characteristics (winds, PV and PV gradients, temperature and temperature gradients, distance from tropopause, etc.), are cataloged for up to five jet cores in each hemisphere at each longitude. In addition to the complex of midlatitude westerly upper tropospheric jets that results in the "subtropical" and "polar" jet structure seen in zonal means, the method also identifies lowlatitude jets, such as the easterly jets that define the tropical edge of monsoon circulations and the downstream westerly jets that are associated with them, as well as the low-latitude jets known as "westerly ducts" (e.g., Horinouchi et al. 2000). The climatologies of all of these are described below.

The subvortex jet is defined as the extension of the stratospheric polar night jet into the lowermost stratosphere (Manney et al. 2011). Subvortex jets are identified as a function of altitude, using criteria based on winds and vertical structure. The algorithm is applied at each MERRA model level between $\sim 300$ and $\sim 14 \mathrm{hPa}$. At each of these levels, a subvortex jet core (white dots in Fig. 1) is identified as the most poleward maximum in westerly wind speed that exceeds $30 \mathrm{~m} \mathrm{~s}^{-1}$ (blue dots along bold yellow lines in Fig. 1). To distinguish between the bottom of a subvortex jet and the top of an upper tropospheric jet, we first identify all potential subvortex jets at levels down to a pressure near $300 \mathrm{hPa}$. We then work down from the level nearest $80 \mathrm{hPa}$ to identify the lowest altitude at which the wind speed of the jet is still decreasing with decreasing altitude; this is defined as the bottom of the subvortex jet. As discussed below, and seen in Fig. 1b (above S2) and Fig. 1d (above N1), "merged" subvortex and upper tropospheric jets are common in winter. A merged jet can be identified as a case where the subvortex jet at the lowest altitude has a wind speed significantly greater than $30 \mathrm{~m} \mathrm{~s}^{-1}$ and the edges of the subvortex jet region (the $30 \mathrm{~m} \mathrm{~s}^{-1}$ wind speed contours on either side of the core) at that lowest level are separated by at least $5^{\circ}$ latitude; these criteria ensure that the lower bound of the subvortex jet was identified by the wind speed beginning to increase with decreasing altitude, rather than by the wind speed becoming less than $30 \mathrm{~m} \mathrm{~s}^{-1}$ (the latter meaning that a defined jet ceased to exist). Although we have not applied our methods to characterize the stratospheric summer easterly jet, it does at times extend down near the tropopause, and its signature appears in figures based on wind speed (e.g., its lowest reaches can be seen in Fig. 1a near $20 \mathrm{~km}$ in the low-latitude $\mathrm{SH}$ as weak easterlies near $10^{\circ} \mathrm{S}$, and in the $\mathrm{NH}$ in Fig. $1 \mathrm{~b}$ overlying the monsoon easterlies).

Dynamical tropopauses are cataloged, defined by PV values in the extratropics from 2.0 to 6.0 potential vorticity units (PVU; $1 \mathrm{PVU}=1.0 \times 10^{-6} \mathrm{~K} \mathrm{~m}^{2} \mathrm{~kg}^{-1} \mathrm{~s}^{-1}$ ), joined with the $380-\mathrm{K}$ potential temperature $(\theta)$ contour where that contour is at higher altitude than the PV contour (typically in the tropics; the 4.5-PVU tropopause is shown as an orange line in Fig. 1). The PV values cover the range that has been widely used to define the extratropical tropopause (e.g., Highwood et al. 2000; Schoeberl 2004; Kunz et al. 2011). The thermal (temperature gradient) tropopause (thick black lines in Fig. 1) is calculated using the World Meteorological Organization (WMO) definition [a review of issues related to definition of the thermal tropopause is given by Homeyer et al. (2010)]. Multiple tropopauses are identified if the lapse rate, $-d T / d z$, drops below 2 $\mathrm{K} \mathrm{km}^{-1}$ above the primary thermal tropopause and then rises above $2 \mathrm{~K} \mathrm{~km}^{-1}$ again (shown as dashed black-andwhite lines in Fig. 1). Randel et al. (2007) showed that using this criterion, rather than requiring the lapse rate to drop farther below the initial threshold in between, results in a climatology of multiple tropopauses in relatively coarse-resolution meteorological analyses comparable to that from higher-resolution measurements such as those from Global Positioning System satellites or radiosondes. Profiles with more than two tropopauses are uncommon, but do occur (e.g., Randel et al. 2007; Añel et al. 2008); while all cases with more than one tropopause are included 

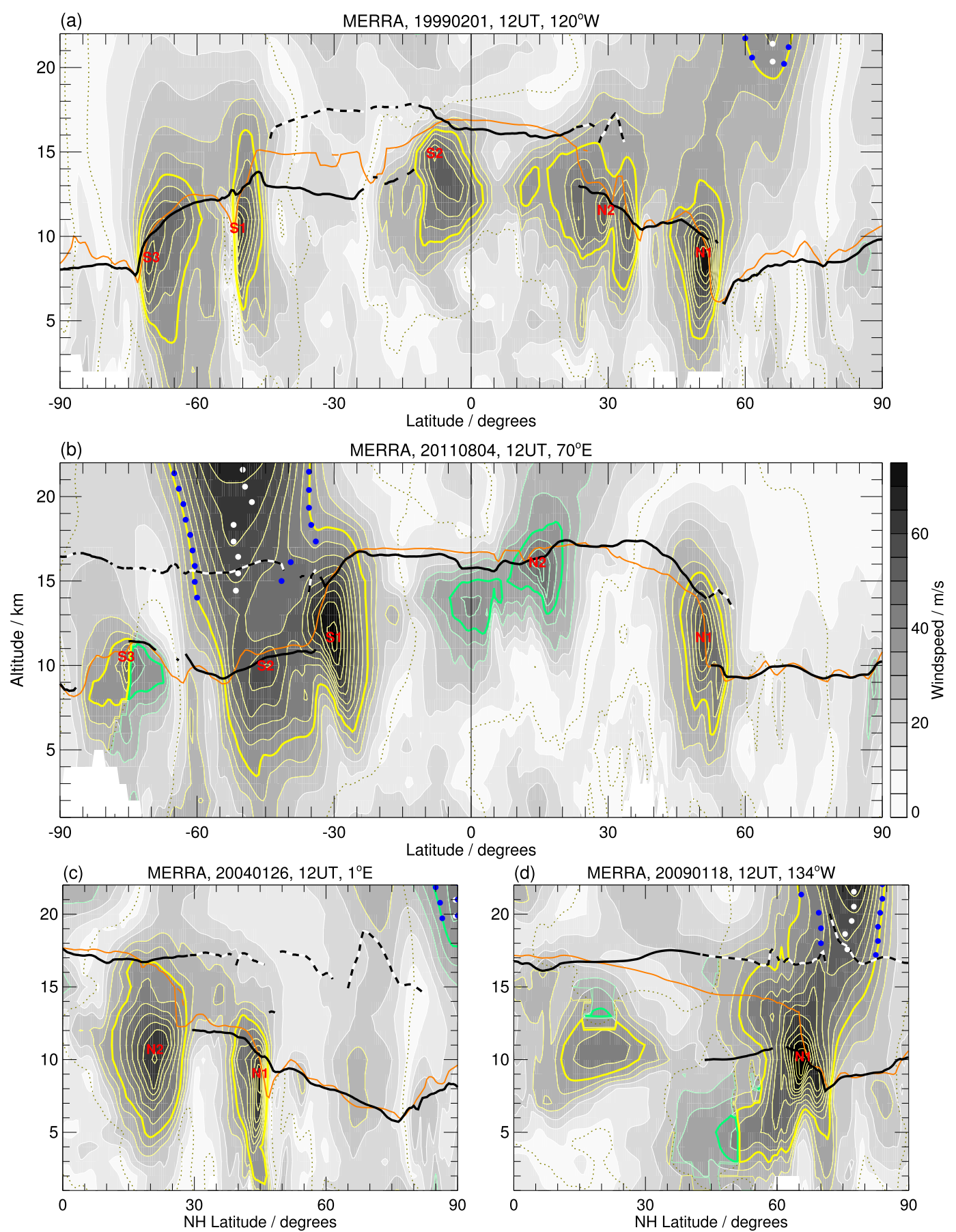

FIG. 1. Cross sections of MERRA wind speed (gray shading); yellow (green) lines outline westerlies (easterlies) with regions with wind speed greater than $20 \mathrm{~m} \mathrm{~s}^{-1}$, with the $30 \mathrm{~m} \mathrm{~s}^{-1}$ contour as a thick line in the corresponding color. Red letter/number combinations indicate the locations of upper tropospheric jet cores according to the classification scheme of Manney et al. (2011); numbers increase with decreasing core (maximum) wind speed in each hemisphere. Thin orange lines show the 4.5-PVU dynamical tropopause and thick black lines the WMO (thermal) tropopause; thick black and white dashed lines show the secondary tropopause. White dots show the subvortex jet maximum and blue dots the edges of the subvortex jet region. Thin dotted olive lines show $0 \mathrm{~m} \mathrm{~s}^{-1}$ zonal winds. The examples shown illustrate common synoptic situations discussed in the text. 
in our analysis, the discussion focuses on the characteristics of the primary and secondary tropopauses.

\section{Seasonal jet and multiple tropopause occurrence}

Seasonal occurrence frequencies for upper tropospheric jets are shown in Fig. 2 for December-February (DJF), March-May (MAM), June-August (JJA), and September-November (SON), along with the average wind speed at the jet cores, with wind vectors overlaid to provide direction information. The frequencies are normalized by the number of days included and the number of longitude grid points, and multiplied by 100 to provide a percentage; thus, if there were always a jet at each longitude grid point in a bin, the value for that bin would be $100 \%$. The ubiquitous broad region of high frequencies from $\sim 20^{\circ}$ to $80^{\circ}$ latitude in both hemispheres emphasizes the continuum of westerly jets that inhabits the extratropics. In the following discussion, we refer to "subtropical" and "polar" jets in relation to the maxima in the frequency distributions that correspond to the jets commonly denoted as such in the classical zonal-mean view; it is clear, however, that the preferred patterns of jets do not follow that simple taxonomy, nor are they expected to because of the complexity of the interplay between the processes controlling them.

The westerly jets in both hemispheres show a structure with high frequencies of both polar and subtropical jets in some longitude sectors joined by regions with a transition between a more persistent single subtropical or polar jet. A more annular structure dominated by a single jet is seen in summer. The overall patterns resemble those reported by Koch et al. (2006).

In the $\mathrm{NH}$ winter and spring (Figs. 2a,b), a strong, zonal jet that shifts slightly poleward toward the east dominates the region from the mid-Atlantic across Africa and Asia (from $\sim 40^{\circ} \mathrm{W}$ past $180^{\circ}$ ); the peak jet frequency bifurcates over the eastern Pacific, where the maximum occurrence shifts strongly poleward, and merges again over eastern North America. Strong and Davis (2008) related a split (as seen in the climatology here) or merged jet over North America in winter to the Pacific-North American teleconnection. A double jet morphology is also seen from about $45^{\circ} \mathrm{W}$ to $45^{\circ} \mathrm{E}$ in Fig. 2a, as the single winter/spring climatological jet over eastern North America tilts poleward into the North Atlantic, and a subtropical jet commonly occurs equatorward of $30^{\circ} \mathrm{N}$. Woollings et al. (2010) showed three preferred positions of the North Atlantic eddy-driven jet in winter, ranging from below $40^{\circ} \mathrm{N}$ to near $60^{\circ} \mathrm{N}$, consistent with the broad and somewhat diffuse frequency maximum seen in the climatology (Fig. 2a, between $\sim 40^{\circ}$ and $65^{\circ} \mathrm{N}$, and $\sim 0^{\circ}$ and $\left.45^{\circ} \mathrm{W}\right)$. $\mathrm{Li}$ and Wettstein
(2012) showed that the upper tropospheric jets in the Pacific are strongly eddy driven, compared to more radiatively driven jets over the Atlantic and Eurasia, consistent with higher latitudinal variability and more frequent multiple jet occurrence over the Pacific and western North America. The Atlantic polar jet has been described as a hybrid, with characteristics of both thermally and eddy-driven jets (e.g., Lee and Kim 2003; Eichelberger and Hartmann 2007; Li and Wettstein 2012). A similar, albeit weaker, pattern is seen in NH fall (Fig. 2d); in NH summer (Fig. 2c), a single frequency maximum dominates around the globe, but greater variability is still seen over the eastern Pacific and western North America.

In the SH winter and spring (Figs. 2c,d), two zonally oriented jets stretch most of the way around the hemisphere in longitude, with a region over the south AtlanticSouth Africa (approximately $45^{\circ} \mathrm{W}-45^{\circ} \mathrm{E}$ ) where the occurrence frequency peak of the subtropical jet tilts poleward to meet that of the polar jet in a "spiral" structure. Williams et al. (2007) showed that this SH spiral jet structure, which begins to form in fall and persists into spring, arises from momentum flux convergence associated with Rossby wave breaking. A separate preferred region for subtropical jets is located east of about $45^{\circ} \mathrm{E}$ with a strong zonal pattern. The formation of this "Australian subtropical westerly jet" is associated with a concentration of outflow from tropical convection in this longitude region; transport related to RWB along this jet contributes to formation of a climatological ozone maximum poleward of this jet (e.g., Hitchman and Rogal 2010; Rogal et al. 2010). Similar, but weaker, features are seen in $\mathrm{SH}$ fall and spring (Figs. 2b,d). In SH summer (Fig. 2a), the highest occurrence frequencies are of a single jet extending from $\sim 30^{\circ} \mathrm{W}$ to $130^{\circ} \mathrm{E}$ south of Africa; this is the only period/region in which the polar jet is more persistent than the subtropical jet. There is a more limited region with two zonally oriented jets over the Pacific.

Figures $2 \mathrm{e}-\mathrm{h}$ show that in general the strongest jets are associated with the highest frequencies, with strongest (weakest) jets in winter (summer) in each hemisphere. Except in summer, the $\mathrm{NH}$ jets are stronger than those in the $\mathrm{SH}$ in the corresponding season.

The jet characterization methodology also captures tropical jet systems. The westerly ducts (e.g., Horinouchi et al. 2000; Homeyer et al. 2011) are represented in equatorward bulges (to $\sim 10^{\circ} \mathrm{N}$ ) in $\mathrm{NH}$ subtropical jet frequencies centered near $135^{\circ}$ and $30^{\circ} \mathrm{W}$ in $\mathrm{NH}$ winter (DJF, Fig. 2a). Examination of individual maps shows persistent tongues of high $\mathrm{PV}$ extending into the tropics in the region of the eastern Pacific westerly duct, and low PV from the tropics extending into the subtropics. Tropical/subtropical and interhemispheric transport 

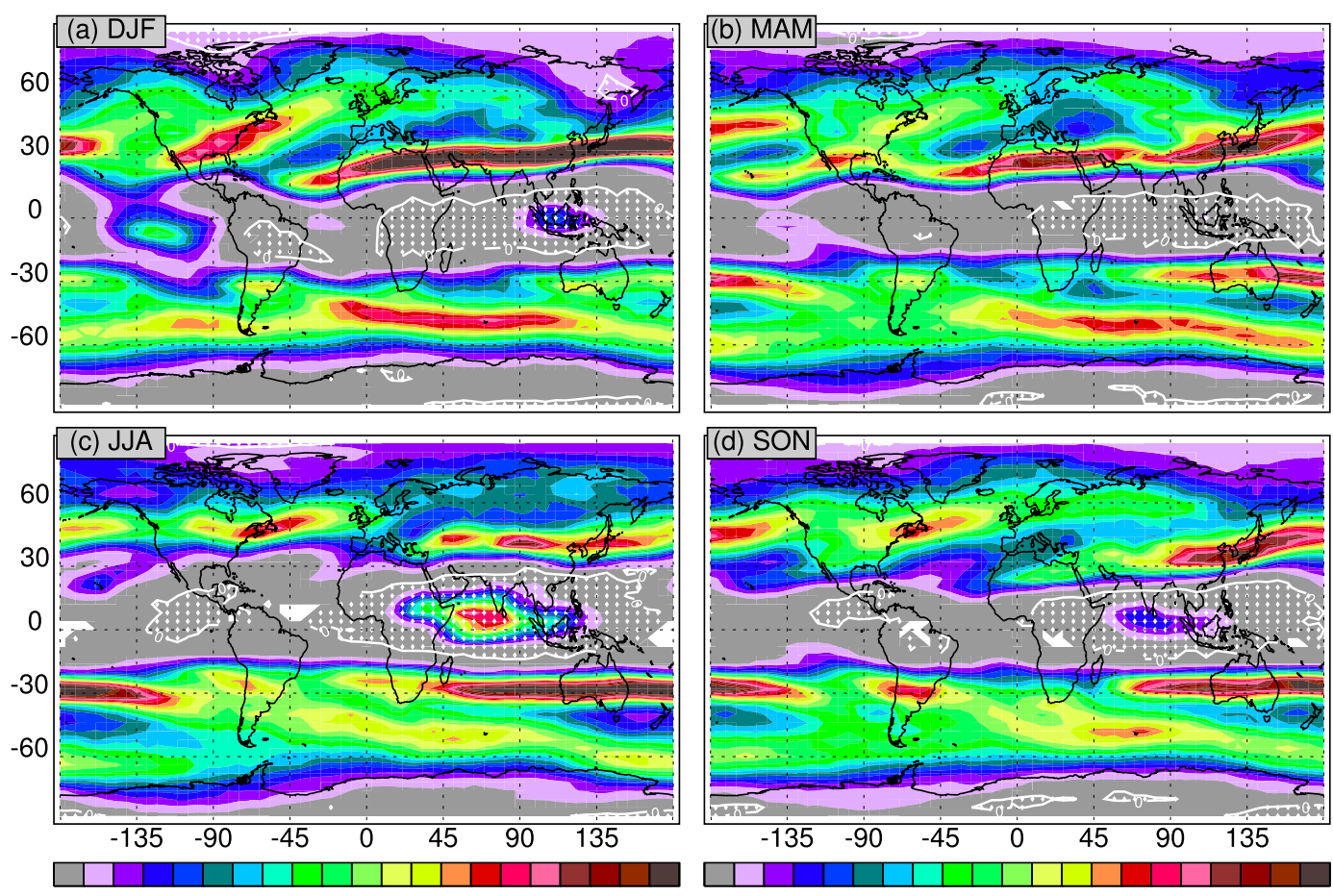

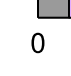

$$
\stackrel{6}{6} \begin{array}{ccc}
12 & 18 & 24 \\
\text { Normalized Jet Core Frequency }
\end{array}
$$
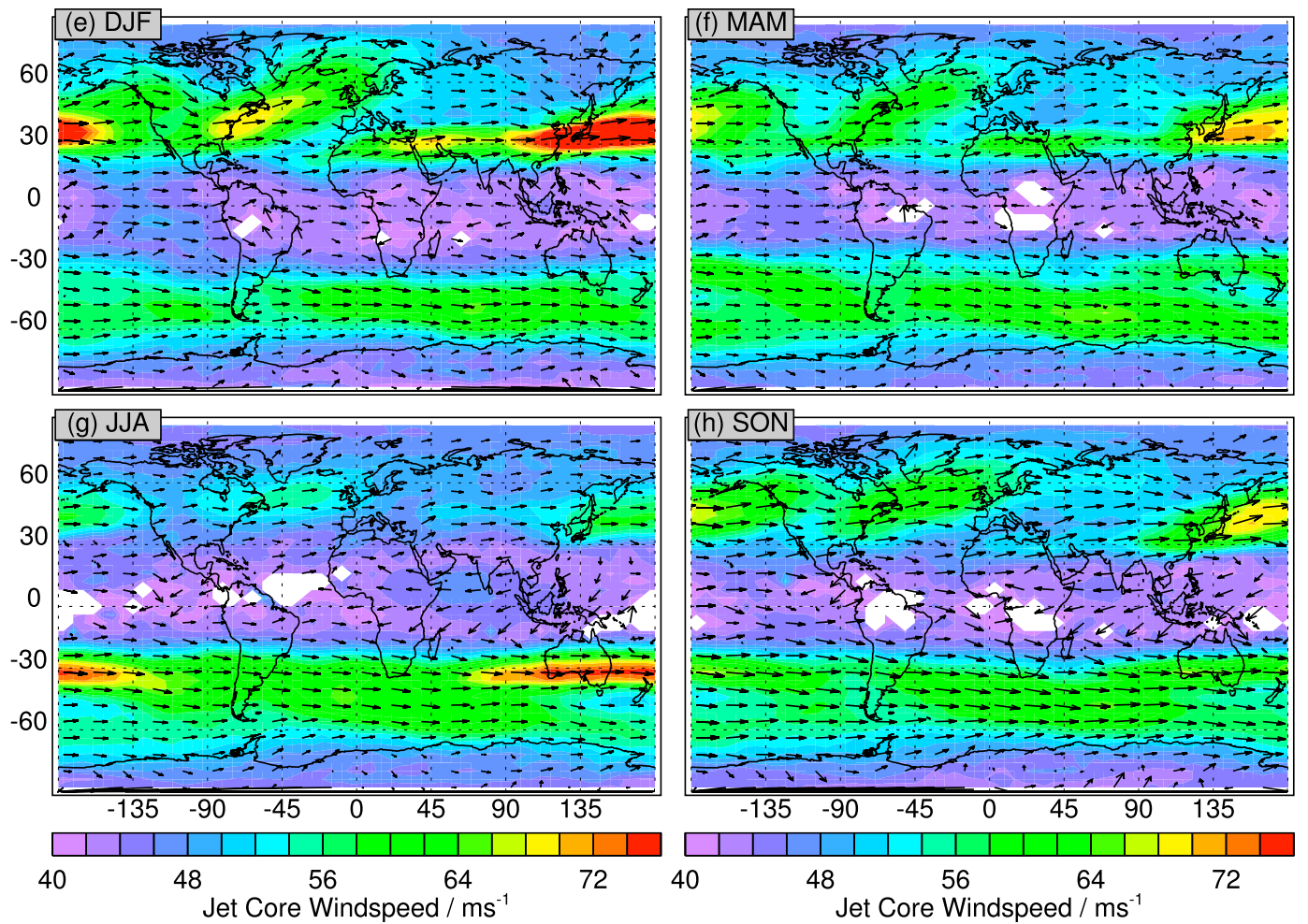

FIG. 2. (a)-(d) Seasonal maps for 1979 through 2012 of the occurrence frequency of upper tropospheric jets and (e)-(h) average wind speed at the jet cores with overlaid wind vectors. As described in section 2b, each jet included is located at the altitude of the maximum wind speed within the 100-400-hPa layer. DJF, MAM, JJA, and SON are shown in (a),(e); (b),(f); (c),(g); and (d),(h), respectively. Normalization in (a)-(d) is such that a value of $100 \%$ represents the case where there is always a jet core at each longitude grid point in the bin. Maximum values in saturated regions are near $50 \%$. Regions of easterly jets in (a)-(d) are shaded with white dots. 
associated with RWB events such as these has been shown to occur preferentially in the westerly ducts (e.g., Kiladis and Weickmann 1992; Kiladis 1998; Waugh and Polvani 2000; Horinouchi et al. 2000). The eastern Pacific westerly duct lies across the equator from a region of strong, persistent westerlies in the $\mathrm{SH}$ tropics from about $100^{\circ}$ to $140^{\circ} \mathrm{W}$. These two jets are related to a manifestation of the "Gill solution" (Gill 1980) in which convective heating gives rise to upper-level westerlies (low-level easterlies) downstream of low-level westerlies (upperlevel easterlies) such as those seen in monsoon regions (e.g., Sardeshmukh and Hoskins 1988) (in this case, the easterlies of the Australian monsoon, which are also apparent in Fig. 2 a between $\sim 90^{\circ}$ and $135^{\circ} \mathrm{E}$ ). The typical synoptic structure associated with the SH summer tropical westerly jet is shown in Fig. 1a, with a strong upper-level jet centered near $5^{\circ}-10^{\circ} \mathrm{S}, 13-15 \mathrm{~km}$ altitude overlying weaker low-level easterlies. This is a case, common in SH summer, where the other SH upper tropospheric jets are far poleward, and the tropopause break occurs across the tropical westerly jet.

In $\mathrm{NH}$ summer/SH winter (Fig. 2c), the dominant tropical feature is the strong, persistent easterly jet $\left(\sim 30^{\circ}-100^{\circ} \mathrm{E}\right)$ that forms the southern branch of the Asian summer monsoon circulation. The subtropical westerly jet at this time shifts from equatorward to poleward of the Tibetan Plateau (from $\sim 30^{\circ} \mathrm{N}$ to $\sim 35^{\circ}-$ $40^{\circ} \mathrm{N}$ ), as described by Schiemann et al. (2009). Figure $1 \mathrm{~b}$ shows an example of the vertical/latitudinal structure of the winds in the Asian summer monsoon region, wherein the characteristic upper-level easterlies (near $15^{\circ} \mathrm{N}, 15 \mathrm{~km}$ ) overlie weaker low-level westerlies.

A NH tropical westerly jet is seen to persist east of the Asian summer monsoon easterlies near $145^{\circ}-175^{\circ} \mathrm{W}$, in a pattern analogous to that seen in DJF in the SH, although with weaker, less persistent westerlies. Park et al. (2007) showed the horizontal structure associated with this Gill-solution feature. The jet characterization method also captures the easterlies associated with the North American (Fig. 2c, $\sim 90^{\circ}-135^{\circ} \mathrm{W}$ ) and South American (Fig. 2a, $\sim 30^{\circ}-60^{\circ} \mathrm{W}$ ) monsoons; the downstream westerlies associated with these monsoons are weaker and less distinct than those associated with the Asian and (especially) Australian monsoons.

The climatology of the subvortex jet bounding the lower part of the stratospheric winter polar vortex is shown in Fig. 3. The bottom of the subvortex jet often merges with the top of an upper tropospheric jet (e.g., Manney et al. 2011; Santee et al. 2011), as can be seen in Figs. $1 \mathrm{~b}$ and $1 \mathrm{~d}$. Figures $3 \mathrm{a}-\mathrm{d}$ show the occurrence frequency of all subvortex jets (merged and unmerged, as defined in section $2 \mathrm{~b}$ ). In Figs. $3 \mathrm{e}-\mathrm{h}$, we plot the percentage of those jets that are merged (shown only where the occurrence frequency for all subvortex jets is greater than $0.5 \%$ ), with the merged jet frequency overlaid.

As expected from the colder and deeper stratospheric vortex in the $\mathrm{SH}$, subvortex jet frequencies are much larger and cover more of the annual cycle in the $\mathrm{SH}$ than in the NH. Subvortex jets start to become common, most of them unmerged, in SH fall (Figs. 3b,f). In SH winter and spring, subvortex jets are persistent (Figs. 3c,d); over $80 \%$ of them are merged from $\sim 135^{\circ} \mathrm{W}$ to $135^{\circ} \mathrm{E}$ in winter, and at all longitudes in spring. The highest merged jet percentages are nearly $100 \%$ in spring between $\sim 30^{\circ} \mathrm{W}$ and $100^{\circ} \mathrm{E}$ longitude; in this region, the polar jet is the most prominent upper tropospheric jet and is shifted equatorward to more closely underlie the subvortex jet than in other longitude regions where it is poleward of the subvortex boundary (Figs. 2c,d). The spatial distribution is very similar in fall (and, based on examination of monthly fields, not shown, in December), as seen in Figs. 3b,f, but weaker, with more unmerged than merged jets in most regions. Examination of monthly maps shows that SH subvortex jets are absent in January through March and very infrequent in April; the nonzero values in DJF (Fig. 3a) are from occurrences in December, and those in MAM (Fig. 3b) primarily from frequent occurrences in May.

In the NH, merged jets in winter and spring (Figs. 3e,f) occur preferentially over the North Atlantic (usually north of $60^{\circ} \mathrm{N}$ ), and over Asia (usually south of $60^{\circ} \mathrm{N}$ and sometimes shifted south of $\left.40^{\circ} \mathrm{N}\right)$; these are preferred regions for displacement of the stratospheric vortex (e.g., Manney et al. 1996; Waugh and Randel 1999; Harvey et al. 2002). Comparing with the upper tropospheric jet frequencies in Fig. 2, it can be seen that the North Atlantic is a preferred region for upper tropospheric jets at high latitudes (also see Woollings et al. 2011). These upper tropospheric jets are associated with strong ridges, RWB, and poleward transport (e.g., Woollings et al. 2011), which link them to the formation of "mini-holes" in column ozone (e.g., Manney et al. 1996; Orsolini et al. 1998; Hood et al. 2001; Allen and Nakamura 2002). The peak in subvortex jet frequency, also associated with a high percentage of merged jets, near $40^{\circ} \mathrm{N}, 135^{\circ} \mathrm{E}$ in DJF (Figs. 3a,e) corresponds to cases in NH winter when a highly distorted stratospheric vortex (typically associated with a stratospheric sudden warming) extends into the lowermost stratosphere, overlying the upper tropospheric jets that are common in the same regions/seasons (Fig. 2); an example of the synoptic structure is shown in Fig. 1d. There is an additional wintertime maximum in subvortex jet frequency (largely unmerged) north of $60^{\circ} \mathrm{N}$ near $135^{\circ}-180^{\circ}$ (Figs. 3a,e). NH subvortex jets are absent in May through September, and uncommon in October. 

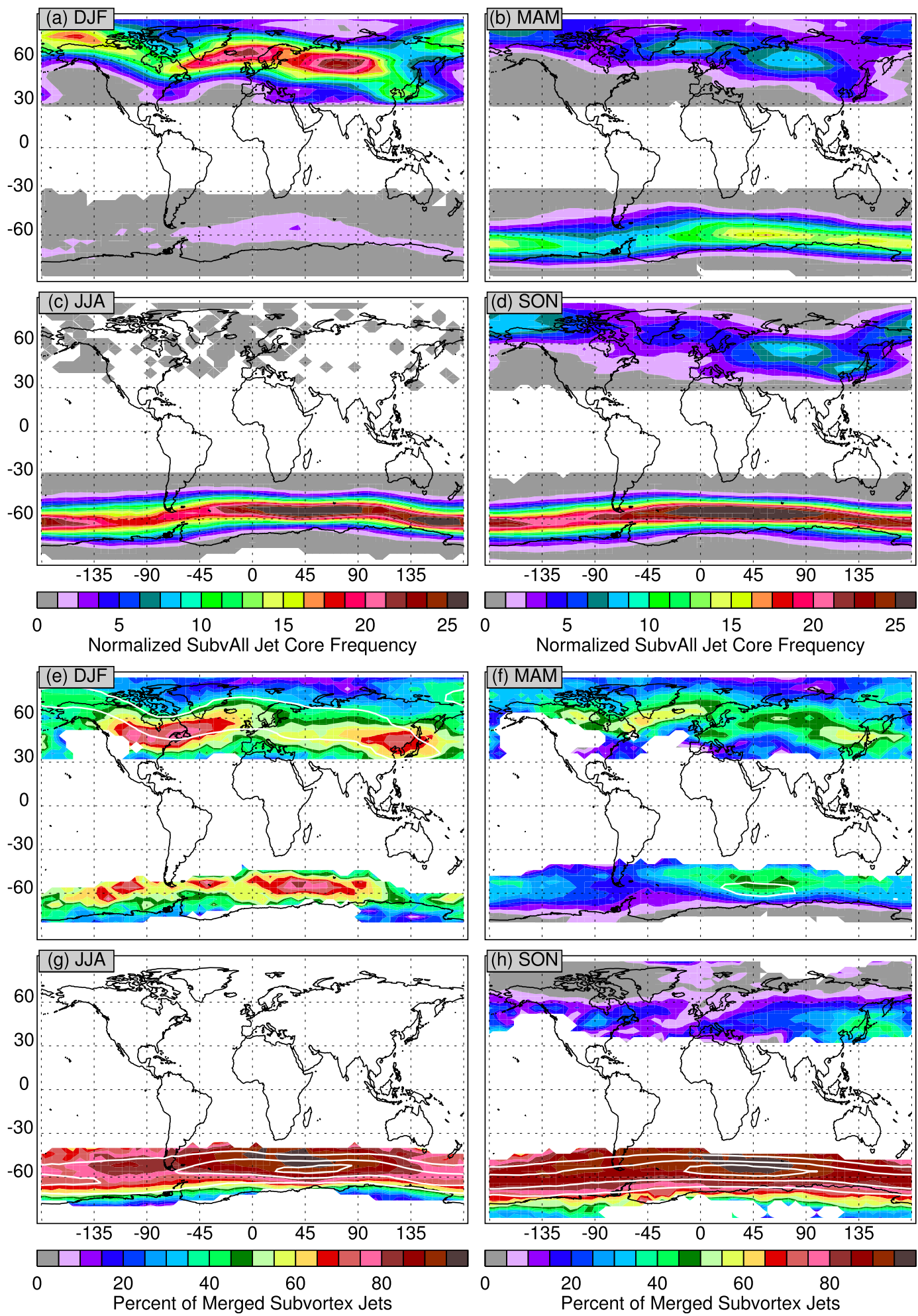

FIG. 3. Seasonal maps for 1979 through 2012 of the occurrence frequency of (a)-(d) any subvortex jet and (e)-(h) the percentage of subvortex jets that are "merged" (i.e., their lowest level joins with the top of an upper tropospheric jet); percentages are not shown where the total subvortex jet frequency is less than $0.5 \%$. Merged subvortex jet frequencies of $5 \%, 15 \%$, and $25 \%$ are overlaid on (e)-(h) in white. Layout and normalization are as in Fig. 2. 
Figure 4 shows the frequency distribution of multiple tropopauses (Figs. 4a-d) and the average distance between the primary and secondary tropopauses (Figs. $4 \mathrm{e}-\mathrm{h}$ ). In each hemisphere, there is a band of high multiple tropopause frequencies in all seasons extending poleward from the latitude of the subtropical jet frequency maximum (Fig. 2). These multiple tropopauses are most frequent and/or persistent in winter and spring in both hemispheres, and more common in the $\mathrm{NH}$ than in the $\mathrm{SH}$ in the corresponding season. There are strong maxima in multiple tropopause frequency over North America (from $\sim 130^{\circ}$ to $50^{\circ} \mathrm{W}$ ) and extending across northern Africa from $\sim 20^{\circ} \mathrm{W}$ to $60^{\circ} \mathrm{E}$. These multiple tropopauses arise when the higher tropical tropopause extends poleward over the lower midlatitude tropopause. The distance between the primary and secondary tropopauses (Figs. 4e-h) increases poleward of the subtropical jets, as the primary tropopause altitude decreases, while the secondary tropopause altitude remains nearly constant [as seen in the examples in Fig. 1, and shown by Randel et al. (2007)]. Distances between primary and secondary tropopauses in the band following that jet are typically $4-7 \mathrm{~km}$. These patterns of midlatitude multiple tropopauses are consistent with previous climatologies (e.g., Randel et al. 2007; Añel et al. 2008) that used higher vertical resolution, but geographically sparser, datasets. Plots similar to Fig. 4 limited to 2005-07 show significant differences from the 34-yr climatology (e.g., less of a dip in frequencies over China in DJF and MAM, a pronounced eastward/equatorward tilt of the high frequency band at $\sim 180^{\circ}-130^{\circ} \mathrm{W}$, higher values near $40^{\circ} \mathrm{S}$ over South America in JJA) and agree closely with the distributions shown by Peevey et al. (2012) using High Resolution Dynamics Limb Sounder (HIRDLS) data for those years.

A significant $(5 \%-10 \%$ of points in the bin, lavender region from $\sim 30^{\circ}$ to $80^{\circ} \mathrm{E}$ in Fig. $4 \mathrm{c}$ ) region of multiple tropopauses appears over the equator during JJA, with the secondary tropopause typically $3-5 \mathrm{~km}$ above the primary. The origin of these has not been studied in detail. However, Sprenger et al. (2003) showed local peaks in stratosphere-to-troposphere and troposphereto-stratosphere transport in the region, associated with dynamical tropopause folds, which might, in turn, be reflected in the thermal structure. Alternatively, Randel et al. (2007) noted that tropical multiple tropopauses were usually associated with large-amplitude stratospheric waves, which were in turn shown by Randel and $\mathrm{Wu}$ (2005) to vary coherently with deep convection (such as that in the Asian monsoon region at this time).

Multiple tropopauses are also common poleward of the subvortex jet in both hemispheres, in fall, winter, and spring. Their longitude variations are, however, often not closely correlated with those of either the subvortex jet or the upper tropospheric jets. Previous studies have noted that identification of the thermal tropopause in polar, especially the $\mathrm{SH}$, winter is uncertain because temperatures typically continue to decrease far above the point where the lapse rate first exceeds $2 \mathrm{~K} \mathrm{~km}^{-1}$ (e.g., Bethan et al. 1996; Highwood et al. 2000; Zängl and Hoinka 2001; Wilcox et al. 2012). Figure 5 illustrates the polar winter tropopause structure in temperature profiles poleward of $60^{\circ}$ in the winters of 2005-12 in each hemisphere. SH temperatures typically decrease up to above $20 \mathrm{~km}$, and the high mean and large standard deviation in single tropopause altitudes arise from inclusion of cases where the lapse rate does not quite reach the required threshold near $10 \mathrm{~km}$ (a typical single tropopause altitude) and, thus, a primary tropopause is identified near $16-20 \mathrm{~km}$. In contrast, the vast majority of Antarctic profiles with multiple tropopauses have a primary tropopause near $10 \mathrm{~km}$. Thus identification of single or multiple tropopauses depends on small differences in the temperature profiles. This ambiguity in identifying the thermal tropopause location can be seen in the frequent jumps between high and low altitude primary tropopauses in high SH latitudes in Fig. 1 b.

Examination of temperature maps for the $\mathrm{NH}$ suggests that the region with most high-latitude multiple tropopauses is collocated with the coldest area in the lower stratosphere. The temperature structure leading to these multiple tropopauses is similar to that in the $\mathrm{SH}$ (Fig. 5, right) but, unlike in the $\mathrm{SH}$, is very different from the structure of the single tropopause profiles. Examination of the stratospheric vortex structure (not shown) indicates that high-latitude single tropopauses are most frequently identified under the polar vortex edge, whereas multiple tropopauses are identified when the profiles are at locations where the interior of the vortex is overhead at and above $\sim 15 \mathrm{~km}$, but the vortex edge is overhead between the primary tropopause and $\sim 15 \mathrm{~km}$. This suggests that many of these multiple tropopauses are associated with a stratospheric vortex that either tilts or expands with increasing altitude. Depending on the vertical wind structure, increasing vortex size with height is associated with greater stability (e.g., Waugh and Dritschel 1999; Polvani and Saravanan 2000) and, thus, with a colder vortex more similar to that in the SH. $\mathrm{NH}$ single tropopause altitudes are usually near $10 \mathrm{~km}$, with much less variability than those in the $\mathrm{SH}$.

$\mathrm{NH}$ high-latitude multiple tropopauses also occur in association with variations across an upper tropospheric jet, as illustrated in Figs. 1c and 1d. Such features are commonly seen in winters with strong stratospheric sudden warmings, and the secondary tropopause may extend $20^{\circ}-50^{\circ}$ poleward from the high "tropical" (extending to $\sim 40^{\circ} \mathrm{N}$ in Fig. 1d) tropopause. Situations like that in 

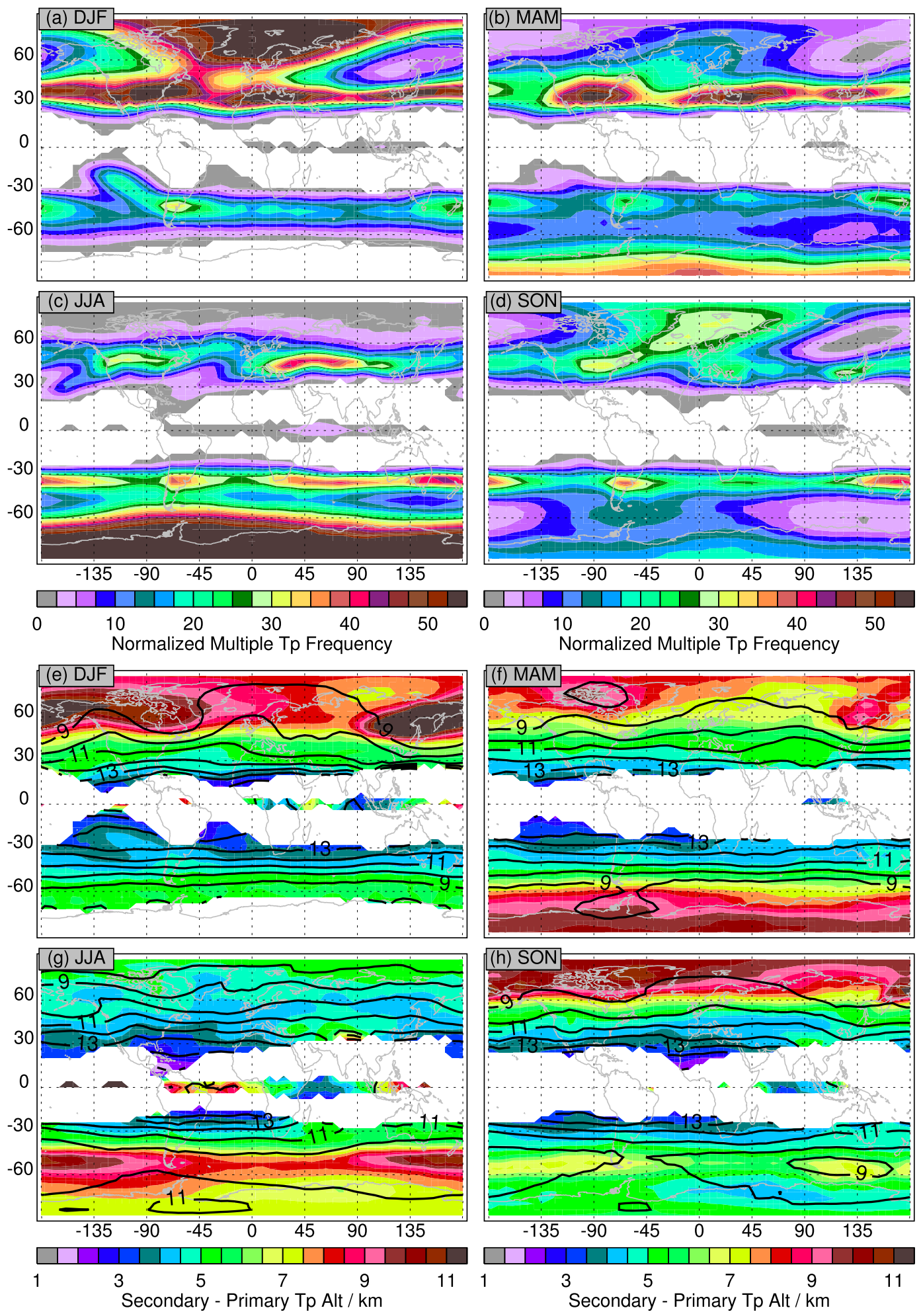

FIG. 4. Seasonal maps for 1979 through 2012 of (a)-(d) the occurrence frequency of multiple WMO tropopauses and (e)-(h) the distance between primary and secondary tropopauses, with the altitude of the primary tropopause overlaid in black (contours 1-km intervals from 8 to $14 \mathrm{~km}$ ). Normalization in (a)-(d) is such that a value of $100 \%$ indicates that there is a multiple tropopause at every grid point in the bin. Frequencies are shown only where they exceed $0.5 \%$. Layout is as in Fig. 2 . 


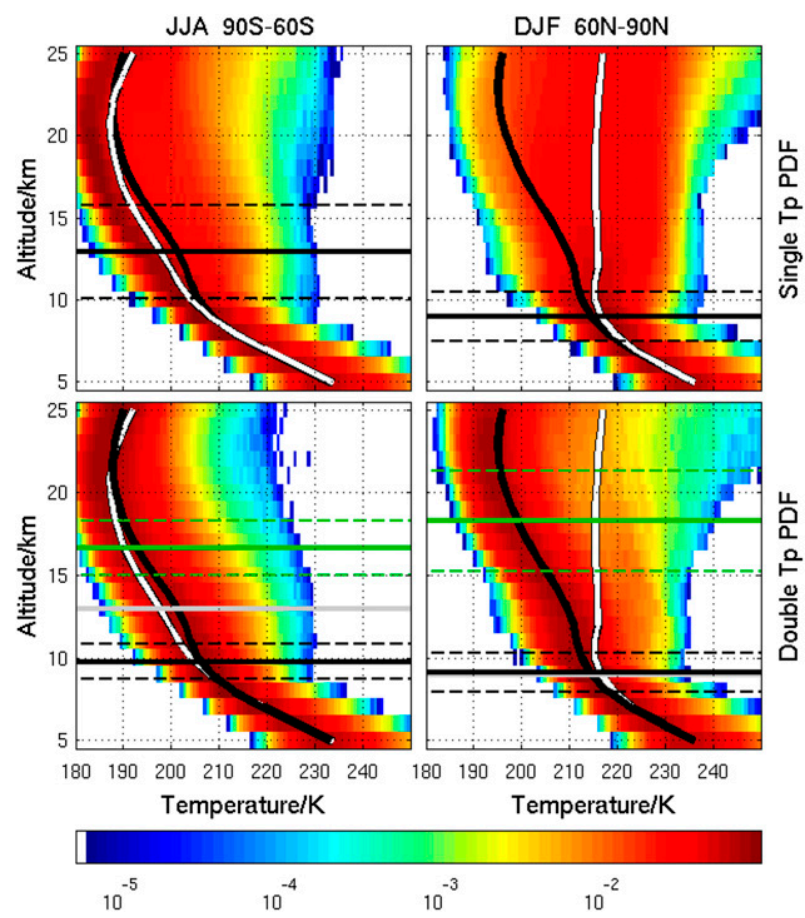

FIG. 5. PDFs of MERRA temperature profiles in the polar winter [(left) SH in JJA and (right) NH in DJF] from 2005 through 2012 in (top) single and (bottom) multiple tropopause regions. White (black) curves show the median for all single (multiple) tropopause cases. Black (green) solid and dashed horizontal lines show the mean and one standard deviation envelope of the primary (secondary) tropopause altitudes. Figures are constructed from 177036 (231 954) profiles for SH single (multiple) tropopauses, and 224154 (170 073) profiles for $\mathrm{NH}$ single (multiple) tropopauses.

Fig. 1d are not uncommon and arise when very nonzonal jets associated with strong ridges, especially blocking events, meander into high latitudes. Examination of the time sequence of high-latitude multiple tropopauses and jets for numerous winters (not shown) indicates that, during cold winters with a relatively strong, deep subvortex, $\mathrm{NH}$ multiple tropopauses are closely associated with the high-latitude temperature structure. On the other hand, in winters where strong SSWs have caused a vortex breakup, high-latitude multiple tropopauses are typically seen immediately poleward of a high-latitude upper tropospheric jet, which may have some characteristics (such as a large tropopause break) usually associated with the subtropical jet.

Figure 6 shows the seasonal climatology of the altitudelatitude distribution of upper tropospheric jets, the subvortex jet, and the tropopauses in MERRA. The upper tropospheric jet frequency distributions suggest the pattern of a high-altitude (typically near $12 \mathrm{~km}$ ) subtropical jet and a lower altitude, higher latitude jet (near $8-10 \mathrm{~km}, 50^{\circ}-60^{\circ}$ latitude, often less frequent) that is characteristic in zonal means, with the primary tropopause following the level just above the jet cores. The secondary tropopauses associated with the tropopause break across the subtropical jet are typically near $14-17 \mathrm{~km}$ in both midlatitudes and polar regions, and thus are farther above the upper tropospheric jets in the polar regions. Unlike the zonal mean view, however, these PDFs show clearly that there is a continuum of upper tropospheric jets from the subtropics to near the pole, albeit with distinct preferred locations. While jet frequencies are relatively high in all seasons from $\sim 20^{\circ}$ to $70^{\circ}$ latitude, in most cases there is a local minimum near $40^{\circ}$ latitude; an exception to this is in the NH in JJA, when the subtropical westerly jet shifts northward over the Tibetan Plateau (e.g., Schiemann et al. 2009). We will revisit this point in section 5 .

In NH spring (Fig. 6b), in addition to the preferred locations characteristic of a subtropical and polar jet, a third upper tropospheric jet maximum near $\sim 13-14 \mathrm{~km}$, $\sim 20^{\circ} \mathrm{N}$ is associated with the westerly ducts; this feature can also be seen in $\mathrm{NH}$ winter (Fig. 6a) as a more diffuse peak at about $14 \mathrm{~km}$ and $20^{\circ}$ latitude. Similar maxima occur in SH spring and fall (Figs. 6a,b) and are associated with equatorward excursions of jets near $90^{\circ}$ $135^{\circ} \mathrm{W}$ (Figs. 2b,d). The SH subtropical jet in summer (Fig. 6a) is weak and located near $30^{\circ} \mathrm{S}, 13-14 \mathrm{~km}$. In general subtropical jet frequencies are largest in winter and spring, and polar jet frequencies largest in summer and fall. That the frequencies of both show stronger maxima in the $\mathrm{SH}$ [e.g., compare the maxima poleward of $40^{\circ}$ near 9-km altitude in $\mathrm{SH}(\mathrm{NH})$ in DJF (JJA), and those equatorward of $40^{\circ}$ near $11-\mathrm{km}$ altitude in $\mathrm{SH}(\mathrm{NH})$ in JJA (DJF)] reflects in large part the smaller degree of variability in jet locations in the $\mathrm{SH}$ than in the $\mathrm{NH}$.

The persistent SH summer tropical westerly jet (near $\sim 90^{\circ}-140^{\circ} \mathrm{W}$ in Fig. 2a) downstream of the Australian monsoon easterlies is shown here to be centered near $15 \mathrm{~km}$, just below the tropical tropopause (with a less pervasive region of easterlies to its north), consistent with the synoptic structure shown in Fig. 1a. The strong tropical easterly jet associated with the Asian summer monsoon circulation is centered near $16 \mathrm{~km}$, closely coincident with the altitude of the tropical tropopause (Figs. 6c,d).

The subvortex jet extends much deeper and more frequently into the lowermost stratosphere in the $\mathrm{SH}$ than in the $\mathrm{NH}$, doing so throughout the winter and spring seasons, and often extending below $12 \mathrm{~km}$ in spring. The NH subvortex jet is significant only in winter and rarely extends much below $15 \mathrm{~km}$. This is consistent with the much stronger, colder, less variable stratospheric vortex in the $\mathrm{SH}$ than in the $\mathrm{NH}$, and with the results of Santee et al. (2011), which showed the implications of this difference for chemical processing and 
(a) DJF 1979--2012

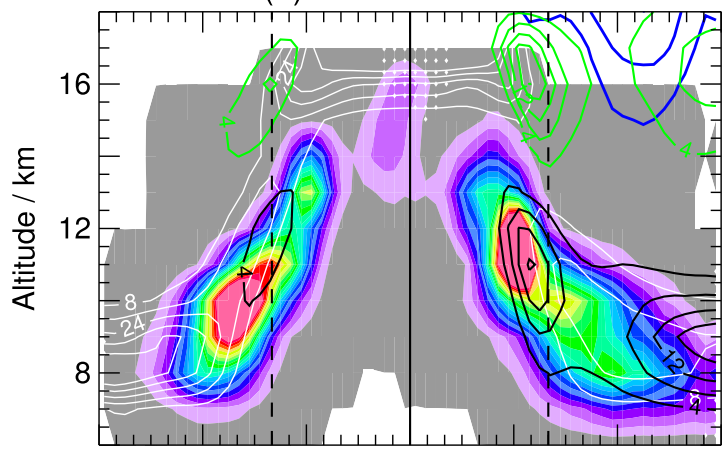

(c) JJA 1979--2012

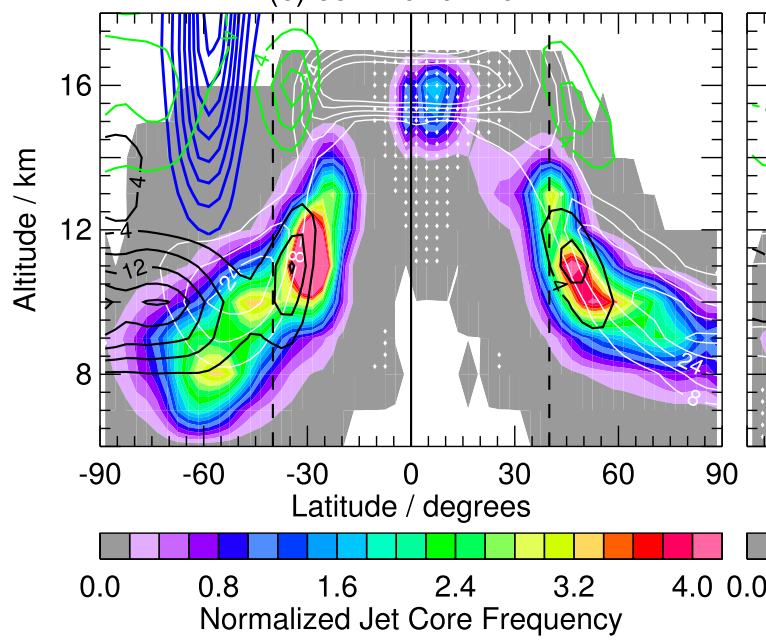

(b) MAM 1979--2012

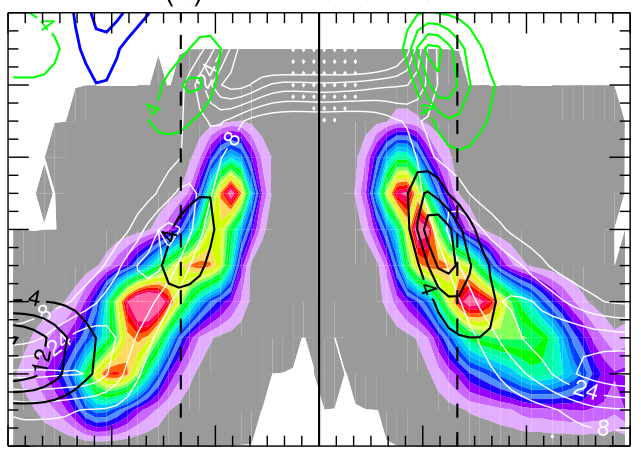

(d) SON 1979--2012

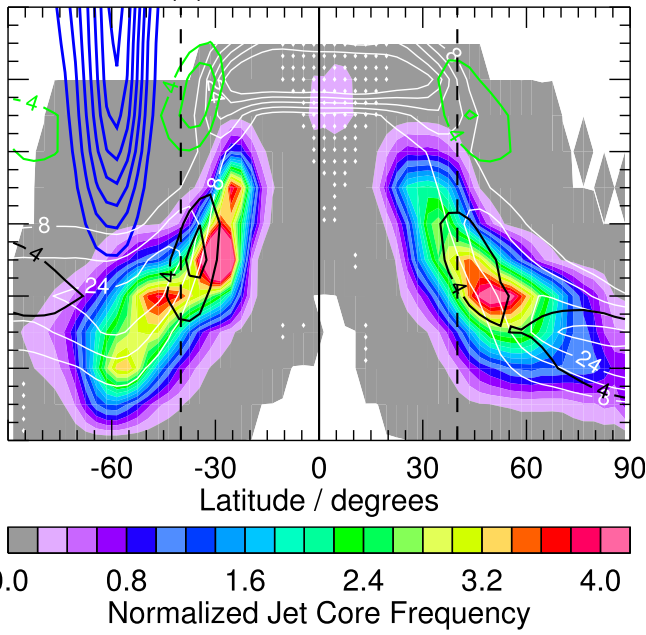

FIG. 6. Latitude-altitude cross sections of seasonal jet frequencies for 1979-2012. Color fill shows upper tropospheric jet frequencies, with white dots demarking regions of easterlies. Blue contours show subvortex jet frequencies; contour interval is $2.0 \%$. White, black, and green contours show frequencies of single tropopauses, and primary and secondary tropopauses for multiple tropopause cases, respectively; contour interval is $8 \%$ for single and $4 \%$ for primary and secondary. Dashed black lines are at $40^{\circ}$ latitude. Normalization is such that a value of $100 \%$ indicates that there is always a jet or tropopause of the indicated type at each grid point in the bin.

ozone loss in the subvortex. That the NH subvortex jet is present only at higher altitudes is consistent with the fact that most merged jets in the NH occur when the subvortex jet is shifted to lower latitudes where the upper tropospheric jets extend to higher altitudes.

In winter the main region of midlatitude primary tropopauses is farther above the upper tropospheric polar jet in the $\mathrm{SH}$ than in the $\mathrm{NH}$ and at higher altitude, near $10 \mathrm{~km}$ in the $\mathrm{SH}$ versus $9 \mathrm{~km}$ in the $\mathrm{NH}$, probably as a consequence of the weaker wave-driven BrewerDobson circulation in the SH (e.g., Shepherd 2002). There is a second region of primary tropopauses in the SH winter at higher altitude, near $12-13 \mathrm{~km}$, reflecting the polar temperature structure shown in Fig. 5. This is consistent with the evidence mentioned above regarding the ambiguity of the thermal tropopause in the SH polar winter. In both hemispheres, the midlatitude and polar secondary tropopauses are most common near 14 $17 \mathrm{~km}$, whereas the primary tropopauses are much lower in the polar regions, consistent with the patterns shown in Figs. $4 \mathrm{e}-\mathrm{h}$.

\section{Annual cycle of jets and multiple tropopauses}

Figure 7 shows the annual cycle, averaged over 1979 through 2012, of upper tropospheric, subvortex, and merged subvortex jet and multiple tropopause frequencies as a function of latitude and time over all longitudes.

The subtropical upper tropospheric jet is always more persistent than the polar jet in the NH (Fig. 7a), with peak subtropical jet frequencies in mid-January through mid-March. There is typically no specific indication that multiple jets exist simultaneously, but rather a broad region of moderate frequencies north of the strong 
subtropical peak. There is, however, a clear indication of separate subtropical and polar jets in mid-March through mid-May, and October through mid-November, at the beginning and end of the period when the subtropical jet shifts northward to near $40^{\circ} \mathrm{N}$. The double peak during these transition periods results partially from the subtropical jet vacillating between higher and lower latitudes (e.g., Schiemann et al. 2009), although some studies also suggest the simultaneous presence of two jets intermittently in the zonal mean (e.g., Bordi et al. 2007, 2008) or in limited longitude sectors (e.g., Eichelberger and Hartmann 2007; Woollings et al. 2010). The broad region of moderate jet frequencies from $\sim 40^{\circ}$ to $60^{\circ} \mathrm{N}$ during most of the year often represents the presence of a polar jet, but sporadic large northward excursions of the subtropical jet, such as during blocking events, also contribute to this pattern. Thus, as shown in section 3, there is no clear distinction between the two jets in the climatological patterns. The lack of a clearly focused polar jet region indicates that the existence, persistence, and positions of the eddy-driven jets are highly variable.

In the $\mathrm{SH}$, the upper tropospheric (Fig. 7a) subtropical jet is most frequent/persistent in June through September, centered near $30^{\circ} \mathrm{S}$ throughout that period. Except during mid-December through February, both polar and subtropical jets are frequently present and distinct, consistent with the structure shown in Fig. 2 and with previous studies (e.g., Koch et al. 2006). The polar jet latitude ranges from $\sim 50^{\circ} \mathrm{S}$ in December and January (when it is the primary SH upper tropospheric jet, see also Fig. 6) to $\sim 55^{\circ}$ to $60^{\circ} \mathrm{S}$ in April through October. While it is less common than is the subtropical jet in June through September, a polar jet distinctly separated from the subtropical jet (when the latter exists) is present throughout the year (this is also apparent in Figs. $6 \mathrm{~b}-\mathrm{d}$ as a distinct local maximum near $8 \mathrm{~km}, 60^{\circ} \mathrm{S}$ ).

The SH subvortex (Figs. 7b,c) begins to strengthen in late March and persists through mid-December. Consistent with the results in section 3 , and with the much stronger, deeper, and less variable $\mathrm{SH}$ subvortex, merged subvortex/upper tropospheric jets (Fig. 7c), while common in winter in both hemispheres, are much more frequent and vary less in latitude in the SH than in the $\mathrm{NH}$. Most SH subvortex jets are unmerged in April and early May, whereas the percentage of merged jets exceeds $50 \%$ in late May and $80 \%$ after mid-June. In July through October, over $90 \%$ of the subvortex jets are merged in most of the latitude region where they are common. Merged jet percentages remain above $50 \%$ into early December in a limited latitude band. In the fall, merged jet frequency increases as the subvortex jet begins to penetrate to lower altitudes and to shift equatorward (seen in Fig. 7b, reflecting an increase in the areal extent of the subvortex), and the upper tropospheric polar jet shifts poleward (Fig. 7a) and lies more directly under the subvortex edge. In spring, the polar vortex breaks up first at higher altitudes, leaving a strong-but more variable in position - jet in the lowermost stratosphere that frequently remains merged with the upper tropospheric polar jet until the subvortex jet retreats poleward (i.e., the subvortex shrinks) and the upper tropospheric jet again shifts equatorward.

The band of multiple tropopauses associated with the subtropical jets in both hemispheres is clearly apparent in Fig. 7d, and a close correlation between higher multiple tropopause frequencies and higher subtropical jet frequencies is apparent. The regions of multiple tropopauses in polar winter are also clear. In both hemispheres, polar multiple tropopauses most commonly form earlier in the season (mid-November through midJanuary in the NH and late May through July in the SH) than the most persistent subvortex. This suggests, particularly in the SH where fewer of these multiple tropopauses are directly associated with the upper tropospheric jets, that the thermal structure discussed above resulting in identification of multiple tropopauses is less common in spring and late winter (after late January in the $\mathrm{NH}$, mid-August in the $\mathrm{SH}$ ) than in fall/early winter.

The region of high upper tropospheric jet frequencies just south of the equator in late December through February is associated with the SH tropical summer westerly jet downstream of the Australian monsoon anticyclone. Figures $8 \mathrm{a}$ and $8 \mathrm{~b}$ show upper tropospheric jet frequency and multiple tropopause plots similar to Fig. 7 , but limited to the $105^{\circ}-135^{\circ} \mathrm{W}$ longitude region where this jet occurs, for October through April. The summer westerly SH tropical jet separates from the $\mathrm{SH}$ subtropical jet in mid-November, and dissipates in late March. A second band of multiple tropopauses forms just poleward of this jet for the duration of its existence. As illustrated in Fig. 1a, when this tropical jet is strong, the tropopause break may occur across it, rather than across a higher-latitude subtropical jet, with a similar characteristic extension of the high tropical tropopause poleward over a lower one. Similar plots of the Australian monsoon region from $90^{\circ}$ to $135^{\circ} \mathrm{E}$ (not shown) indicate persistent equatorial easterlies from early December through mid-March, consistent with the linked generation of these features discussed above.

In the $105^{\circ}-135^{\circ} \mathrm{W}$ region (Figs. $8 \mathrm{a}, \mathrm{b}$ ), the $\mathrm{NH}$ polar jet in fall/winter/spring is more frequent, as well as more clearly separated from the subtropical jet, than in the global view. This is the region over the eastern Pacific and western United States where the upper tropospheric jet frequency pattern splits and both polar and subtropical jets are often present; large excursions of the 

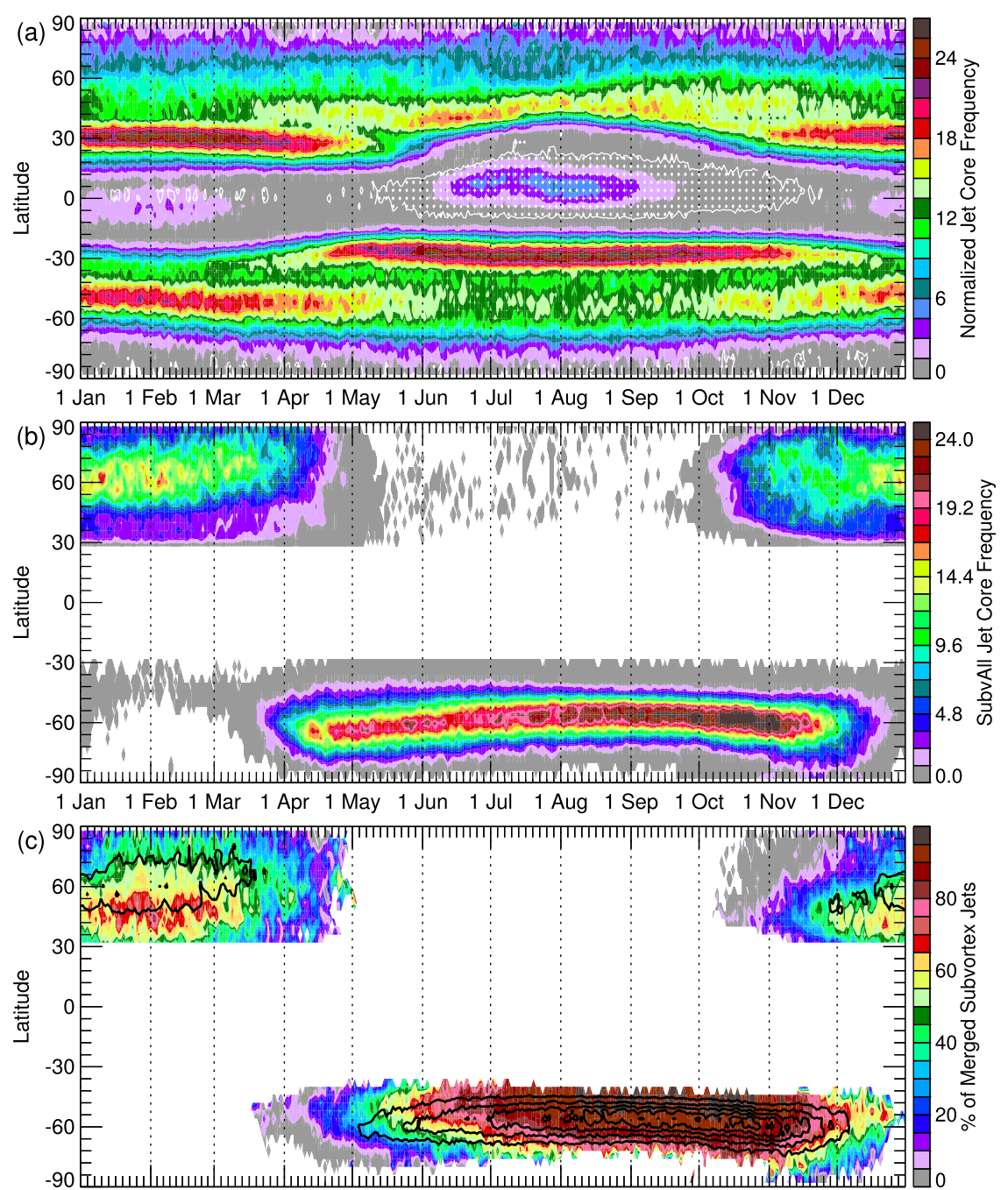

1 Jan 1 Feb 1 Mar 1 Apr 1 May 1 Jun 1 Jul 1 Aug 1 Sep 1 Oct 1 Nov 1 Dec

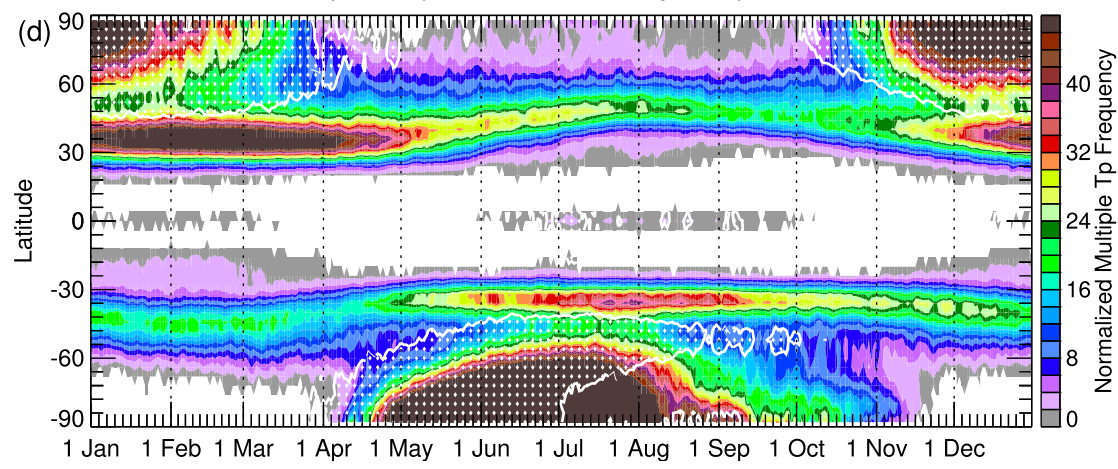

FIG. 7. Annual time series as a function of latitude of climatological (1979-2012) (a) upper tropospheric jet frequencies (regions of easterlies are shaded with white dots), (b) total subvortex jet frequencies, (c) percent of subvortex jets that are merged (black contours show merged subvortex jet frequencies of $5 \%-25 \%$ by $5 \%$ ), and (d) multiple tropopause frequencies (frequencies are shown only where they exceed $0.5 \%$; regions where the distance between primary and secondary tropopauses exceeds $7 \mathrm{~km}$ are shaded with white dots). 
(a)
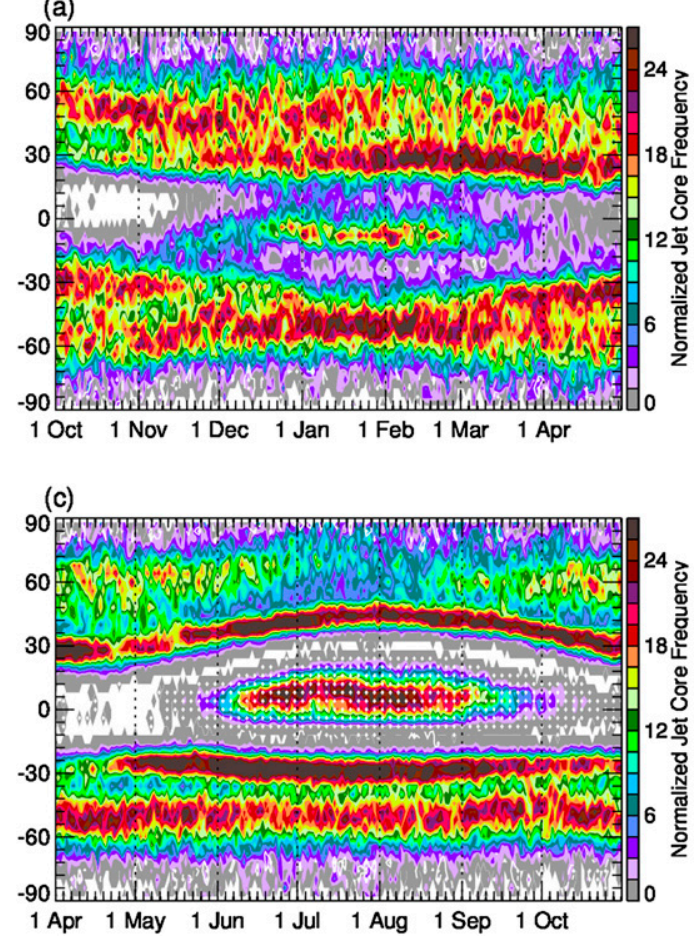

(b)

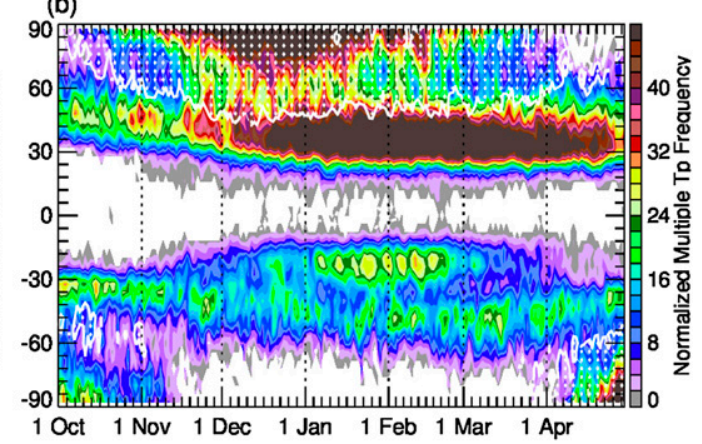

(d)

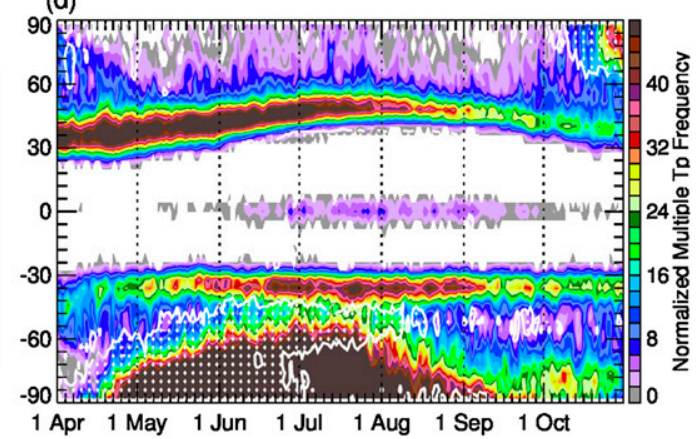

FIG. 8. As in Fig. 7, but for upper tropospheric jets and multiple tropopause frequencies in the limited longitude regions (a),(b) $105^{\circ}-135^{\circ} \mathrm{W}$, for October through April, and (c),(d) $45^{\circ}-90^{\circ} \mathrm{E}$, for April through October.

subtropical jet north of $40^{\circ} \mathrm{N}$ also occur (see Figs. $2 \mathrm{a}, \mathrm{b}$ and discussion thereof).

As noted above, the region of high equatorial jet frequencies in June through August is associated with the Asian summer monsoon circulation. Figures $8 \mathrm{c}$ and $8 \mathrm{~d}$ show the annual cycle of upper tropospheric jets and multiple tropopauses in the $45^{\circ}-90^{\circ} \mathrm{E}$ region from April through October. The easterly branch of the Asian summer monsoon circulation is apparent in late May through early October, during which period the subtropical westerly jet is shifted poleward. This circulation is most persistent in mid-June through mid-August, concurrent with the period when the subtropical jet is at highest latitudes, up to $\sim 45^{\circ} \mathrm{N}$. In contrast to the lower frequencies of upper tropospheric jets seen in the global mean (Fig. 7a), in this region the westerly subtropical jet is nearly as persistent during summer as it is during the rest of the year. In May through mid-August, the multiple tropopauses (Fig. 8d) extending north from the westerly subtropical jet are much more persistent than in the global mean (Fig. 7d). Figure 1b illustrates the synoptic structure giving rise to these patterns. The region of equatorial multiple tropopauses seen in Fig. 4 is present from June through September. Another notable difference in Fig. 8c relative to other longitude regions is that the $\mathrm{SH}$ polar jet is much more, and the $\mathrm{SH}$ subtropical jet somewhat more, persistent in the $45^{\circ}-$ $90^{\circ} \mathrm{E}$ region than in the global view. In this region, the SH polar jet is nearly as persistent as the subtropical jet, indicating that both jets are typically present.

Another view of the longitudinal asymmetries is given in Fig. 9, which shows the upper tropospheric jet frequencies in the $15^{\circ}-45^{\circ}$ latitude band (typically covering the region wherein the subtropical jets reside) in each hemisphere, along with the same view of the frequency of multiple tropopauses. The subtropical jets are most persistent in winter, as described above, but also show preferred longitude regions: $\mathrm{SH}$ jet frequencies are high for the shortest time period (from mid-April to early October) between about $30^{\circ} \mathrm{W}$ and $60^{\circ} \mathrm{E}$, and for the longest period (early April through December) from $\sim 90^{\circ} \mathrm{E}$ to $180^{\circ}$. In the $\mathrm{NH}$, highest frequencies persist through much of the year (September through June) from $\sim 90^{\circ} \mathrm{E}$ to $180^{\circ}$ and are higher in this longitude region than elsewhere throughout the year.

Multiple tropopauses (Figs. 9b,d) are much more common in the $\mathrm{NH}$ than in the SH. Highest multiple tropopause frequencies tend to be shifted westward (upstream) of local (in longitude) maxima in the jet frequencies. The isolated band of high multiple tropopause 

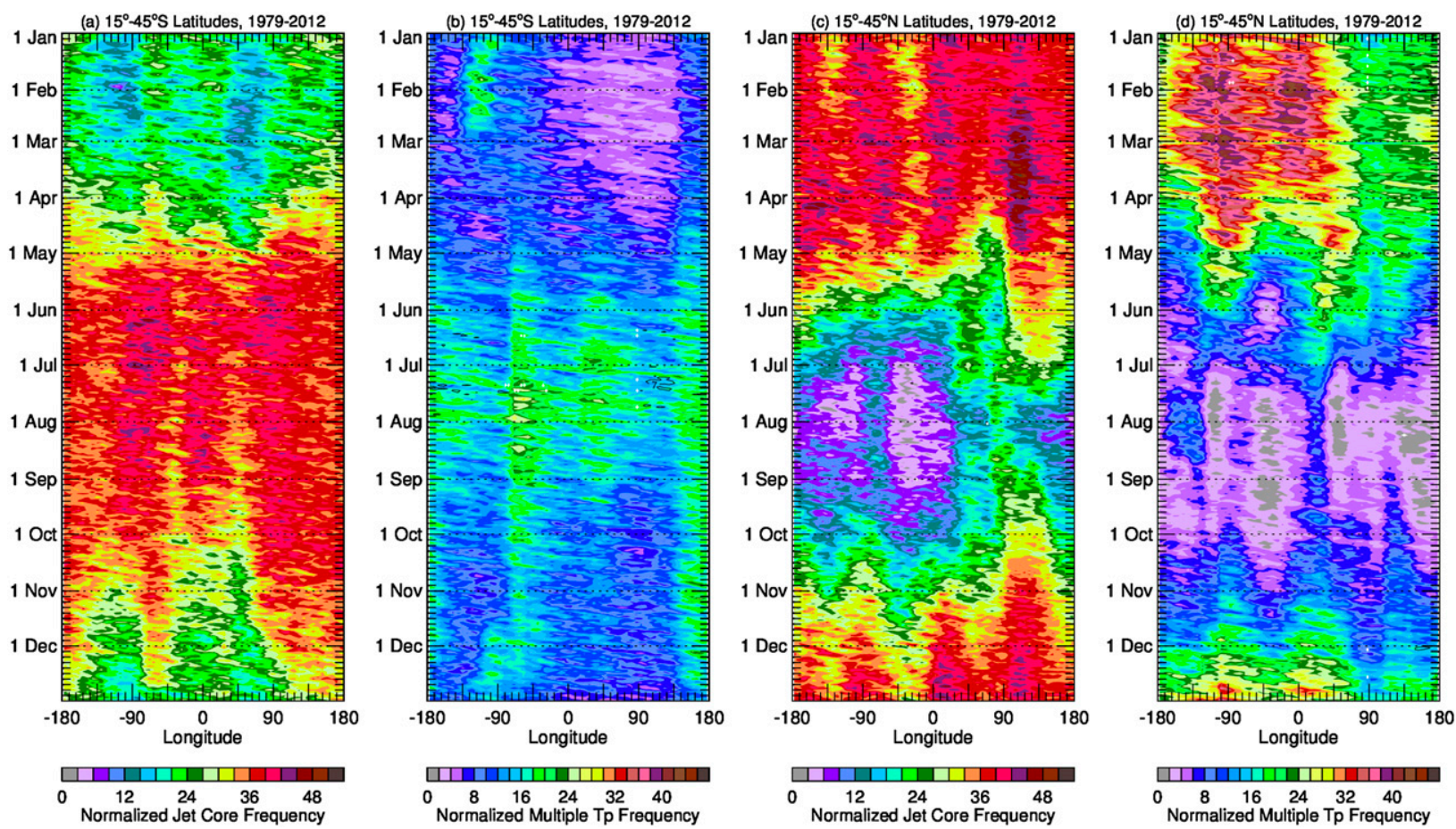

FIG. 9. Annual time series of climatological (1979-2012) upper tropospheric jet and multiple tropopause frequencies as a function of longitude in the $15^{\circ}-45^{\circ}$ (a),(b) south and (c),(d) north latitude bands. See text for description of normalization.

frequencies in the $\mathrm{SH}$ near $120^{\circ} \mathrm{W}$ in December through February is where the tropopause break often occurs across the tropical westerly jet downstream of the Australian monsoon. Multiple tropopause features progress eastward with time (a slope down and to the right in Figs. 9b,d), as do the contemporaneous patterns in jet frequency. These characteristics of the climatological multiple tropopause time evolution resemble the features shown by Peevey et al. (2012) from three years of HIRDLS data. MERRA shows a decrease in multiple tropopause frequencies over China $\left(\sim 80^{\circ}-120^{\circ} \mathrm{E}\right)$, similar to that found by Añel et al. (2008) in a 39-yr record of radiosonde data. Peevey et al. (2012) suggested that this minimum, deeper than that seen in HIRDLS results, could arise from the sparseness of sonde measurements in this region, a factor that could also affect MERRA. However, examination of MERRA for the years with HIRDLS measurements (2005-07) shows a much shallower decrease over China than in the 34-yr climatology, indicating that the difference arises primarily from interannual variations.

\section{A jet-coordinate view}

Manney et al. (2011) demonstrated that using a coordinate system defined by the distance from the upper tropospheric jets is valuable to highlight the relationships of dynamical and transport processes to those jets. As discussed in relation to Fig. 6, there is often a relative minimum in upper tropospheric jet frequency near $40^{\circ}$ latitude, with strong peaks on either side of it representative of subtropical and polar jets. We define the subtropical (polar) jet coordinate as the distance from the strongest jet equatorward (poleward) of $40^{\circ}$ latitude. While this definition is too simplistic for detailed analysis of interannual variability in different regions (e.g., the Asian monsoon region, where the subtropical jet sometimes shifts poleward of $40^{\circ} \mathrm{N}$ ), trends, or case studies, it is appropriate here for providing a broad view of the overall climatology of the jet regions.

Figure 10 show climatologies of wind speed (overlaid contours of negative zonal wind demark easterly regions) for the solstice seasons in a coordinate system with the distance in latitude and altitude from the subtropical (Figs. 10a,c) and polar (Figs. 10b,d) jet cores as horizontal and vertical coordinate. (The MAM and SON distributions show features similar to those in DJF and JJA, respectively.) The PV contours shown, 2 and 6 PVU, are near the lower and upper bounds of the range commonly used to define the dynamical tropopause (e.g., Kunz et al. 2011). The locations where multiple tropopauses are most common are also indicated, along 
with contours of $d T / d z$ surrounding the $-2 \mathrm{~K} \mathrm{~km}^{-1}$ threshold that defines the WMO tropopause. Regions with a high frequency of negative latitudinal PV gradients, a diagnostic of RWB [associated with enhanced transport, Homeyer and Bowman (2013) and references therein], are also indicated. Table 1 gives the subtropical and polar jet core locations, wind speeds, and PV values for all four seasons. The subtropical jet in both hemispheres is typically located near $30^{\circ}$ but shifted to higher latitude in $\mathrm{NH}$ summer and fall because of the poleward shift associated with the Asian summer monsoon circulation. The $\mathrm{NH}$ polar jet sits near $57^{\circ}-58^{\circ} \mathrm{N}$ throughout the year, whereas the $\mathrm{SH}$ polar jet is near $57^{\circ} \mathrm{S}$ in winter but shifts to near $53^{\circ} \mathrm{S}$ in summer. Subtropical jet altitudes are near $11.5-12 \mathrm{~km}$, and polar jet altitudes from 9 to $10 \mathrm{~km}$, with slightly higher altitudes in summer than in winter in both hemispheres. Subtropical jet potential temperatures are typically $345-350 \mathrm{~K}$ and polar jet potential temperatures near $300-320 \mathrm{~K}$, except in $\mathrm{NH}$ summer.

The polar jet is washed out in plots having a coordinate system centered on the subtropical jet, whereas the subtropical jet is washed out in plots having a coordinate system centered on the polar jet. That is, the polar jet appears as a weak local maximum $1-5 \mathrm{~km}$ below and $20^{\circ}-30^{\circ}$ poleward of the origin in Figs. 10a and $10 \mathrm{c}$, made with respect to the subtropical jet. Conversely, the subtropical jet appears as a weak maximum near $1-5 \mathrm{~km}$ above and $20^{\circ}-30^{\circ}$ equatorward of the origin in Figs. 10b and 10d, made with respect to the polar jet. This muting of the jet features arises from averaging together values in a bin where the "non-coordinate" jet occurs only sporadically because both jets are not always present at the same times and/or longitudes or their relative latitudes and/or altitudes vary (Manney et al. 2011).

The subtropical jet is strongest in winter (Figs. 10a,c) and spring and slightly stronger in the $\mathrm{NH}$ than in the $\mathrm{SH}$ during the same season, except during summer (Fig. 10, Table 1). High easterly wind speeds in the tropics in the $\mathrm{NH}$ in summer (Fig. 10c) between $\sim 2$ and $6 \mathrm{~km}$ above the jet are associated with the Asian summer monsoon circulation. A similar, though weaker, feature in the SH summer (Fig. 10a) is associated with the Australian monsoon. The SH tropical westerlies that accompany the Australian monsoon are not obvious here because they are often identified as the subtropical jet (and, indeed, often constitute the jet across which the tropopause break occurs), as discussed in relation to Figs. 2 and 6. The stratospheric summer easterly jet is apparent, overlying the monsoon-related features, and is stronger in $\mathrm{NH}$ than in $\mathrm{SH}$ summer. The 2-PVU potential vorticity contour in all seasons and both hemispheres passes near the core of the subtropical jet and is nearly vertical at that point, consistent with the results of Kunz et al. (2011) relating the strongest PV gradients on isentropic surfaces (hence PV most nearly perpendicular to the surface) to maximum wind speed. Table 1 shows that PV at the subtropical jet core is slightly higher (in absolute value) in the SH (typically $\sim 2.1 \mathrm{PVU}$ ) than in the $\mathrm{NH}$ ( $\sim 1.6 \mathrm{PVU})$. The tropopause as indicated by this $\mathrm{PV}$ contour drops from $\sim 3-4 \mathrm{~km}$ above the subtropical jet core on the equatorward side to $\sim 1-2 \mathrm{~km}$ below it on the poleward side.

The SH winter subvortex jet extends down nearly to the core of the subtropical jet (Fig. 10c). To the extent that all three jet regions are encompassed by the same $24 \mathrm{~m} \mathrm{~s}^{-1}$ contour, there is incomplete separation between upper tropospheric polar and subtropical jets and the subvortex jet. In contrast, because the NH stratospheric vortex is much warmer, weaker, and more variable, the NH subvortex jet rarely extends below $12 \mathrm{~km}$ and its lowest reaches remain $\sim 5-8 \mathrm{~km}$ above the subtropical jet core (Fig. 10a). This hemispheric difference in subvortex jets was evident in the jet-frequency climatology (e.g., Figs. 3 and 6). The polar jet wind speeds are slightly stronger in the $\mathrm{SH}$ than in the $\mathrm{NH}$, strongest in SH spring and weakest in NH summer. The tropopause also drops across the polar jet, but (consistent with the smaller vertical extent of the polar jet) only from about $1-2 \mathrm{~km}$ above it on the equatorward side to $1-$ $2 \mathrm{~km}$ below it on the poleward side. That this drop is much more obvious here than in cross sections of all jet/ tropopause frequencies shown in Fig. 6 reflects that the polar and subtropical jets are often not prominent at the same time: Since the subtropical jet is often stronger and/or more persistent, the average over all conditions is dominated by the large drop across the subtropical jet. $\mathrm{PV}$ at the polar jet core is 2-3 PVU, with variations correlated with the altitude and potential temperature of the jet (Table 1).

Regions with high frequencies of negative latitudinal PV gradients (solid black contours in Fig. 10) indicate frequent or persistent Rossby wave breaking. The frequencies given here are calculated as the fraction of total points in each bin with negative values, and thus do not provide detailed information as to the time or small spatial scale variations. However, although RWB occurs sporadically in localized regions, the jet-coordinate view favors detecting it since it is particularly common on the flanks of the jets (e.g., Hitchman and Huesmann 2007; Homeyer and Bowman 2013). Surrounding the subtropical jet, the strongest RWB is in the NH in summer (Fig. 10c), with an extensive region on the equatorward flank and a small region near the tropopause on the poleward flank. In NH summer, SH winter (both JJA), and SH spring (not shown) there is a small region just 

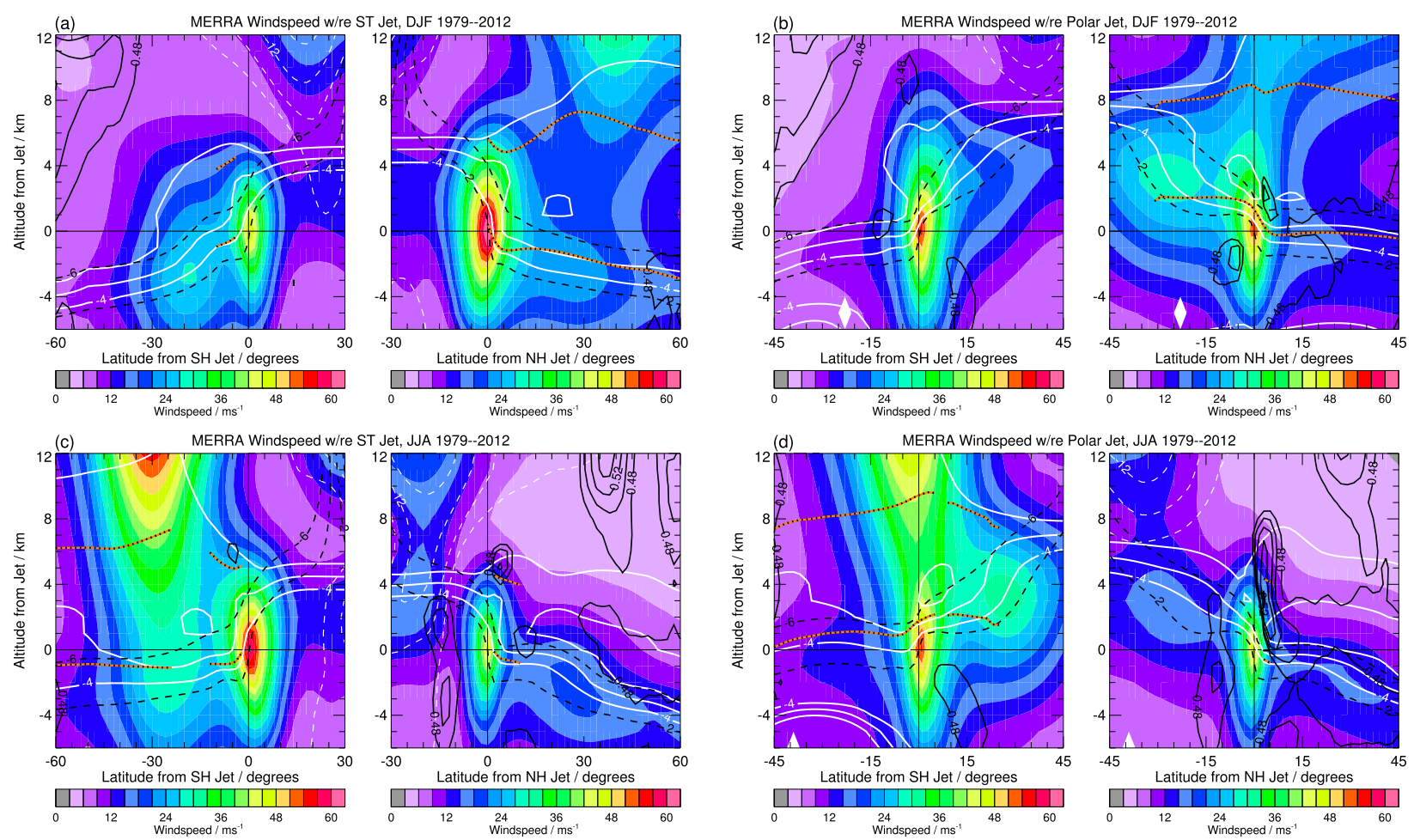

FIG. 10. Mean seasonal MERRA wind speed (colors, $\mathrm{ms}^{-1}$; thin dashed white contours are zonal winds from -28 to 0 by $4 \mathrm{~m} \mathrm{~s}^{-1}$, demarking regions of easterlies) in coordinates relative to the (a),(c) subtropical and (b),(d) polar upper tropospheric jets (see text), for (top) DJF and (bottom) JJA. Thick solid white contours show $d T / d z$ values of $-4,-2$, and $0 \mathrm{~K} \mathrm{~km}^{-1}$. Thin solid black contours are high frequencies of negative latitudinal potential vorticity (PV) gradient (expressed as the fraction of points in a bin with $\mathrm{PV}_{y} \leq 0$, from 0.48 to 0.56 by 0.02 ). Thick dashed black lines are 2- and 6-PVU contours. Orange/black dashed lines show the average primary and secondary WMO tropopause locations wherever there are multiple tropopauses more than $20 \%$ of the time.

poleward of and above the jet, just above the tropical tropopause (similarly located regions appear at other times if a lower-frequency contour is plotted); this is consistent with reports of a common pathway for isentropic poleward transport from the top of the tropical tropopause region into the lower stratosphere (e.g., Rosenlof et al. 1997; Hegglin and Shepherd 2007; Bönisch et al. 2009; Pan et al. 2009; Homeyer et al. 2011).
Regions of RWB are also seen below and equatorward of the polar jet (Figs. 10b,d) in both hemispheres and all seasons, with the strongest and most extensive such regions in the NH in summer. Significant RWB regions poleward of and above the polar jet are seen in the $\mathrm{NH}$ in all seasons, again strongest and most extensive in summer. Eddy-zonal flow feedbacks related to RWB are essential to "self-maintenance" of the eddy-driven

TABLE 1. Mean seasonal jet position and characteristics.

\begin{tabular}{|c|c|c|c|c|c|c|c|c|}
\hline \multirow[b]{2}{*}{ Field } & \multicolumn{4}{|c|}{ Subtropical jet } & \multicolumn{4}{|c|}{ Polar jet } \\
\hline & DJF & MAM & JJA & SON & DJF & MAM & JJA & SON \\
\hline $\mathrm{NH}$ latitude $\left({ }^{\circ} \mathrm{N}\right)$ & 29.0 & 28.8 & 35.4 & 33.0 & 57.7 & 56.9 & 57.8 & 57.2 \\
\hline SH latitude ( $\left.{ }^{\circ} \mathrm{S}\right)$ & 31.6 & 30.1 & 29.0 & 29.3 & 52.8 & 55.7 & 56.9 & 54.9 \\
\hline $\mathrm{NH}$ altitude $(\mathrm{km})$ & 11.5 & 11.9 & 12.1 & 11.9 & 8.9 & 9.1 & 10.2 & 9.6 \\
\hline SH altitude $(\mathrm{km})$ & 12.1 & 11.9 & 11.4 & 11.4 & 9.4 & 9.0 & 8.9 & 9.1 \\
\hline $\mathrm{NH} \theta(\mathrm{K})$ & 344 & 344 & 350 & 345 & 304 & 317 & 344 & 324 \\
\hline $\mathrm{SH} \theta(\mathrm{K})$ & 346 & 345 & 343 & 342 & 317 & 318 & 311 & 316 \\
\hline NH PV (PVU) & 1.6 & 1.6 & 2.0 & 1.7 & 2.1 & 2.3 & 3.2 & 2.6 \\
\hline SH PV (PVU) & -2.3 & -2.1 & -2.1 & -2.0 & -2.6 & -2.3 & -2.0 & -2.2 \\
\hline $\mathrm{NH}$ wind speed $\left(\mathrm{m} \mathrm{s}^{-1}\right)$ & 65.0 & 56.7 & 47.5 & 53.1 & 52.7 & 50.1 & 46.0 & 52.7 \\
\hline SH wind speed $\left(\mathrm{m} \mathrm{s}^{-1}\right)$ & 49.4 & 53.5 & 61.3 & 55.4 & 53.8 & 54.8 & 53.2 & 53.1 \\
\hline
\end{tabular}


jets (e.g., Lorenz and Hartmann 2003; Robinson 2006; Bordi et al. 2007; Barnes and Hartmann 2011; Garfinkel et al. 2013) that are the zonal mean analog of the polar jets shown here, consistent with more pervasive RWB associated with these polar jets. Strong RWB regions are also seen in the polar lower stratosphere $(\sim 6-12 \mathrm{~km}$ above the upper tropospheric jets) in both hemispheres in summer. The patterns of RWB are consistent with the patterns shown in the climatology of Hitchman and Huesmann (2007).

Multiple tropopauses occur more than $20 \%$ of the time in all seasons extending from $\sim 0^{\circ}$ to $15^{\circ}$ poleward of the subtropical jet, covering $\sim 10^{\circ}-20^{\circ}$ latitude depending on season and hemisphere (the largest extent is in the NH in spring, not shown). In winter, they are common throughout the region poleward of the subtropical jet, reflecting the added presence of the highlatitude multiple tropopauses discussed above. The secondary tropopause at high latitudes is typically 7 $9 \mathrm{~km}$ above the primary tropopause in fall and winter, while immediately poleward of the subtropical jet the secondary tropopause is $\sim 4-6 \mathrm{~km}$ above the primary. The separation immediately poleward of the subtropical jet is consistent with the 4-6-km drop in the primary tropopause height since the secondary tropopause extends poleward near the altitude of the primary tropical tropopause. Most of the increase in separation with latitude occurs at the latitude of the polar jet, indicating a change in character to that of the polar tropopauses discussed above (section 3; Figs. 4 and 6). The $d T / d z$ contours (white overlays) do not closely follow the multiple tropopause structure because they are an average over single and multiple tropopause cases. However, they do generally suggest a folded structure in regions near the upper tropospheric jets where multiple tropopauses are common. Folding is less obvious in the polar winter regions, consistent with multiple tropopauses there originating primarily from subtle variations in the polar lower stratospheric thermal structure as shown in Fig. 5.

\section{Summary and conclusions}

A climatology of upper tropospheric-lower stratospheric (ULTS) jets in MERRA from 1979 through 2012 is presented. Using recently developed methods of characterizing UTLS jets and tropopauses (Manney et al. 2011), we show the seasonal patterns and evolution of the upper tropospheric jets in relation to the subvortex jet (the lowest portion of the stratospheric polar night jet that extends into the lowermost stratosphere) and to regions with multiple tropopauses.
The upper tropospheric jets form a continuum, with significant occurrence frequencies throughout the $20^{\circ}-$ $80^{\circ}$ latitude region in both hemispheres. Strong peaks in this distribution indicate preferred patterns that vary with season and hemisphere. In the $\mathrm{NH}$, a nearly zonal subtropical jet stretches from the mid-Atlantic across Africa and Asia throughout the year, strongest in winter and spring. In NH winter and spring, and weakly in fall, the upper tropospheric jet splits into a subtropical and polar jet over the eastern Pacific and merges again over eastern North America. This single jet then tilts poleward over the North Atlantic, resulting in a double-jet pattern over the Atlantic and Europe. In the $\mathrm{SH}$, upper tropospheric subtropical and polar jets typically extend around most of the globe, forming a spiral structure in winter and spring. In summer and fall, the polar jet is commonly the more persistent of the two.

The vertical structure of the UTLS jets and tropopauses shows a continuum within which the higheraltitude subtropical jet and lower-altitude polar jet that are characteristic in the zonal mean view are prominent. The primary tropopause follows the level just above the jet cores. Secondary tropopauses cluster poleward of the subtropical jet near $15-17-\mathrm{km}$ altitude. The SH subvortex jet extends several kilometers down into the altitude region where upper tropospheric jets are common, extending lowest during spring; the NH subvortex jet barely overlaps this region.

A band with frequent multiple tropopauses extends poleward from the subtropical jet location in all seasons, where the higher tropical tropopause extends poleward over the top of the subtropical jet, and tropospheric intrusions are common. Multiple tropopauses in this subtropical to midlatitude band are most frequently found slightly west (upstream) of the maximum subtropical jet frequencies. Most frequent subtropical to midlatitude multiple tropopauses are seen in $\mathrm{NH}$ winter to spring, with highest frequencies and broadest latitude extent over North America. These midlatitude multiple tropopauses are typically $5-7 \mathrm{~km}$ above the primary tropopause, consistent with previous studies.

Multiple tropopauses are pervasive in the highlatitude SH in fall and winter (May through August), usually associated with the unique thermal structure of the Antarctic polar vortex region. High-latitude multiple tropopauses are also common in the $\mathrm{NH}$ in fall and winter and during cold winters are usually associated with a polar vortex temperature structure similar to that in the SH. In warmer, more disturbed winters, some polar multiple tropopauses are directly related to a higher tropopause extending poleward over a lower one 
across an upper tropospheric jet (either the polar jet or a subtropical jet that has shifted to high latitude during, e.g., a blocking event). High-latitude multiple tropopauses are usually farther above the primary tropopause than the midlatitude ones, with a typical separation of $7-10 \mathrm{~km}$.

Viewing the upper tropospheric jets averaged with their cores at the origin highlights several additional features of their climatology:

- The subtropical jet, at $\sim 12-\mathrm{km}$ altitude, is strongest in winter and, except in spring, slightly stronger in the $\mathrm{NH}$ than in the SH.

- The polar jet, at $\sim 9-\mathrm{km}$ altitude $(10 \mathrm{~km}$ in the $\mathrm{NH}$ in summer), is stronger than the subtropical jet in the $\mathrm{SH}$ in fall through spring, but weaker than the subtropical jet in all seasons in the $\mathrm{NH}$.

- The 2-PVU contour of PV, consistent with its common use to demark the dynamical tropopause, passes near the core of both subtropical and polar jets and is nearly vertical at that point. $\mathrm{PV}$ at the subtropical jet core is slightly lower in the NH than in the SH, and slightly higher at the polar than the subtropical jet cores.

- The primary tropopause drops $\sim 4-6 \mathrm{~km}$ across the subtropical jet and $\sim 2-4 \mathrm{~km}$ across the polar jet.

- Evidence of Rossby wave breaking near the upper tropospheric jets is most commonly seen poleward of the $\mathrm{NH}$ polar jet in summer.

The signature of the Asian summer monsoon circulation is a strong tropical easterly jet in $\mathrm{NH}$ summer from $\sim 40^{\circ}$ to $100^{\circ} \mathrm{E}$, accompanied by a northward and upward shift of the westerly subtropical jet. In a manifestation of the "Gill solution" circulation driven by convection associated with low-level heating, a westerly tropical upper tropospheric jet is seen to the east of this monsoon circulation. In the SH summer, the Australian monsoon circulation is accompanied by a strong, persistent westerly jet in the $\mathrm{SH}$ tropics in the eastern $\mathrm{Pa}$ cific. The westerly jet eastward of the Australian monsoon is stronger and more persistent than that associated with the Asian summer monsoon, and a region of multiple tropopauses forms poleward of it. The westerly ducts in $\mathrm{NH}$ winter and spring are seen as higher jet frequencies at low latitudes in $\mathrm{NH}$ winter and spring over the eastern Pacific and the Atlantic; the westerly duct in the eastern Pacific is part of the Gill-solution pattern associated with the Australian monsoon.

Situations where the subvortex jet merges with an upper tropospheric jet are very frequent in the $\mathrm{SH}$ in May through December and have a maximum in the longitude region where the upper tropospheric jet frequencies show a pattern with the subtropical jet spiraling poleward to merge with a more persistent polar jet. The
SH subvortex jet is persistent beginning in May, but is usually unmerged through June; it is nearly always merged with an upper tropospheric jet in July through mid-November. Merged jets in the $\mathrm{NH}$, while not as ubiquitous as those in the $\mathrm{SH}$, occur frequently in November through April and are most common over the North Atlantic and at latitudes equatorward of $60^{\circ} \mathrm{N}$ over Asia. Merged upper tropospheric and subvortex jets may have implications for transport and wave propagation: A merged jet extending over a sufficient longitude range may mean that the transport barrier represented by the stratospheric polar vortex (Schoeberl et al. 1992; Manney et al. 1994; Bowman 1996, and references therein) extends into the upper troposphere. Nishii et al. (2011) showed that blocking events can enhance or suppress propagation of Rossby waves into the stratosphere depending on their geographical location. The dependence of wave propagation on the three-dimensional relationships between upper tropospheric and stratospheric winds has not, to our knowledge, been explored in detail. The view presented here linking the upper tropospheric and stratospheric jets provides a framework for future studies exploring these interactions.

Several aspects of the spatial and temporal frequency distributions of upper tropospheric jets from MERRA shown here reflect behavior that is consistent with the results of previous studies using other methods and different datasets. This provides high confidence in the MERRA UTLS dynamical fields, which had not heretofore been studied in detail. Our results also extend those of previous studies to provide a global 34-yr climatology, and to show the relationships between upper tropospheric jets, the stratospheric subvortex, and multiple tropopauses. Follow-up work will examine interannual variability and long-term changes in the UTLS jets, and use the jet-coordinate framework to examine transport in trace-gas climatologies from reanalysis and satellite datasets.

Acknowledgments. Thanks to the MLS team at JPL, especially Nathaniel Livesey, Brian Knosp, Ryan Fuller, Vince Perun, and Robert Thurstans, for scientific, data management/processing, and computational support. Thanks to NASA's High-End Computing Program for computational resources used for MERRA, to Michele Rienecker and other colleagues at NASA's GMAO for their advice on using MERRA, and to the Goddard DAAC for distributing the data. Thanks to Dennis Hartmann, Brian Hoskins, Kirstin Krüger, Ken Minschwaner, Dave Raymond, Ted Shepherd, and Gui-Ying Yang for helpful discussions. Thanks to the three anonymous reviewers for very helpful comments. Work at the Jet Propulsion Laboratory, California 
Institute of Technology, was done under contract with the National Aeronautics and Space Administration.

\section{REFERENCES}

Allen, D. R., and N. Nakamura, 2002: Dynamical reconstruction of the record low column ozone over Europe on 30 November 1999. Geophys. Res. Lett., 29, 1362, doi:10.1029/2002GL014935.

Añel, J. A., J. C. Antuña, L. Torre, and J. M. Castanheira, 2008: Climatological features of global multiple tropopause events. J. Geophys. Res., 113, D00B08, doi:10.1029/2007JD009697.

Archer, C. L., and K. Caldeira, 2008: Historical trends in the jet streams. Geophys. Res. Lett., 35, L08803, doi:10.1029/ 2008 GL033614.

Barnes, E. A., and D. L. Hartmann, 2011: Rossby wave scales, propagation, and the variability of eddy-driven jets. J. Atmos. Sci., 68, 2893-2908, doi:10.1175/JAS-D-11-039.1.

Barton, N. P., and A. W. Ellis, 2009: Variability in wintertime position and strength of the North Pacific jet stream as represented by re-analysis data. Int. J. Climatol., 29, 851-862, doi:10.1002/joc.1750.

Bethan, S., G. Vaughan, and S. J. Reid, 1996: A comparison of ozone and thermal tropopause heights and the impact of tropopause definition on quantifying the ozone content of the troposphere. Quart. J. Roy. Meteor. Soc., 122, 929-944, doi:10.1002/ qj. 49712253207.

Bloom, S. C., L. L. Takacs, A. M. da Silva, and D. Ledvina, 1996: Data assimilation using incremental analysis updates. Mon. Wea. Rev., 124, 1256-1271, doi:10.1175/1520-0493(1996)124<1256: DAUIAU $>2.0 . \mathrm{CO} ; 2$.

Bönisch, H., A. Engel, J. Curtius, T. Birner, and P. Hoor, 2009: Quantifying transport into the lowermost stratosphere using simultaneous in situ measurements of $\mathrm{SF}_{6}$ and $\mathrm{CO}_{2}$. Atmos. Chem. Phys., 9, 5905-5919, doi:10.5194/acp-9-5905-2009.

Bordi, I., K. Fraedrich, F. Lunkeit, and A. Sutera, 2007: Tropospheric double jets, meridional cells, and eddies: A case study and idealized simulations. Mon. Wea. Rev., 135, 3118-3133, doi:10.1175/MWR3464.1.

- — - and A. Sutera, 2008: Multiple jets observed in the summer Northern Hemisphere troposphere. Nuovo Cimento, 30, 587-604.

Bowman, K. P., 1996: Rossby wave phase speeds and mixing barriers in the stratosphere. Part I: Observations. J. Atmos. Sci., 53, 905-916, doi:10.1175/1520-0469(1996)053<0905:RWPSAM>2.0.CO;2.

Chang, E. K., S. Lee, and K. L. Swanson, 2002: Storm track dynamics. J. Climate, 15, 2163-2183, doi:10.1175/1520-0442(2002) 015<02163:STD $>2.0 . C O ; 2$.

Davis, S. M., and K. H. Rosenlof, 2012: A multidiagnostic intercomparison of tropical-width time series using reanalysis and satellite observations. J. Climate, 25, 1061-1078, doi:10.1175/ JCLI-D-11-00127.1.

Eichelberger, S. J., and D. L. Hartmann, 2007: Zonal jet structure and the leading mode of variability. J. Climate, 20, 5149-5163, doi:10.1175/JCLI4279.1.

Forster, P. M., and K. P. Shine, 1997: Radiative forcing and temperature trends from stratospheric ozone changes. J. Geophys. Res., 102, 10841-10855, doi:10.1029/96JD03510.

Garfinkel, C. I., D. W. Waugh, and E. P. Gerber, 2013: The effect of tropospheric jet latitude on coupling between the stratospheric polar vortex and the troposphere. J. Climate, 26, 20772095, doi:10.1175/JCLI-D-12-00301.1.

Gettelman, A., P. Hoor, L. L. Pan, W. J. Randel, M. I. Hegglin, and T. Birner, 2011: The extratropical upper troposphere and lower stratosphere. Rev. Geophys., 49, RG3003, doi:10.1029/ 2011RG000355.

Gill, A. E., 1980: Some simple solutions for heat-induced tropical circulation. Quart. J. Roy. Meteor. Soc., 106, 447-462, doi:10.1002/ qj. 49710644905 .

Grise, K. M., L. M. Polvani, G. Tselioudis, Y. Wu, and M. D. Zelinka, 2013: The ozone hole indirect effect: Cloud-radiative anomalies accompanying the poleward shift of the eddy-driven jet in the Southern Hemisphere. Geophys. Res. Lett., 40, 3688 3692, doi:10.1002/grl.50675.

Grotjahn, R., 1993: Global Atmospheric Circulations: Observations and Theories. Oxford University Press, $430 \mathrm{pp}$.

Harnik, N., J. Perlwitz, and T. A. Shaw, 2011: Observed decadal changes in downward wave coupling between the stratosphere and troposphere in the Southern Hemisphere. J. Climate, 24, 4558-4569, doi:10.1175/2011JCLI4118.1.

Harvey, V. L., R. B. Pierce, T. D. Fairlie, and M. H. Hitchman, 2002: A climatology of stratospheric polar vortices and anticyclones. J. Geophys. Res., 107, 4442, doi:10.1029/2001JD001471.

Hegglin, M. I., and T. G. Shepherd, 2007: $\mathrm{O}_{3}-\mathrm{N}_{2} \mathrm{O}$ correlations from the Atmospheric Chemistry Experiment: Revisiting a diagnostic of transport and chemistry in the stratosphere. J. Geophys. Res., 112, D19301, doi:10.1029/2006JD008281.

—, D. Brunner, T. Peter, J. Staehelin, V. Wirth, P. Hoor, and H. Fischer, 2005: Determination of eddy diffusivity in the lowermost stratosphere. Geophys. Res. Lett., 32, L13812, doi:10.1029/2005GL022495.

, C. D. Boone, G. L. Manney, and K. A. Walker, 2009: A global view of the extratropical tropopause transition layer (ExTL) from Atmospheric Chemistry Experiment Fourier Transform Spectrometer $\mathrm{O}_{3}, \mathrm{H}_{2} \mathrm{O}$, and CO. J. Geophys. Res., 114, D00B11, doi:10.1029/2008JD009984.

Held, I. M., and A. Y. Hou, 1980: Nonlinear axially symmetric circulations in a nearly inviscid atmosphere. J. Atmos. Sci., 37, 515-533, doi:10.1175/1520-0469(1980)037<0515:NASCIA > 2.0.CO;2.

— tion between the Hadley cell and a Rossby wave. J. Atmos. Sci., 47, 856-869, doi:10.1175/1520-0469(1990)047<0856: ABMOTI $>2.0 . \mathrm{CO} ; 2$

Highwood, E. J., B. J. Hoskins, and P. Berrisford, 2000: Properties of the Arctic tropopause. Quart. J. Roy. Meteor. Soc., 126, 1515-1532, doi:10.1002/qj.49712656515.

Hitchman, M. H., and A. S. Huesmann, 2007: A seasonal climatology of Rossby wave breaking in the 320-2000-K layer. J. Atmos. Sci., 64, 1922-1940, doi:10.1175/JAS3927.1.

_ , and M. J. Rogal, 2010: Influence of tropical convection on the Southern Hemisphere ozone maximum during the winter to spring transition. J. Geophys. Res., 115, D14118, doi:10.1029/ 2009JD012883.

Homeyer, C. R., and K. P. Bowman, 2013: Rossby wave breaking and transport between the tropics and extratropics above the subtropical jet. J. Atmos. Sci., 70, 607-626, doi:10.1175/ JAS-D-12-0198.1.

Homeyer, C., K. P. Bowman, and L. L. Pan, 2010: Extratropical tropopause transition layer characteristics from high-resolution sounding data. J. Geophys. Res., 115, D13108, doi:10.1029/ 2009JD013664.

Homeyer, C. R., K. P. Bowman, L. L. Pan, E. L. Atlas, R.-S. Gao, and T. L. Campos, 2011: Dynamical and chemical characteristics of tropospheric intrusions observed during START08. J. Geophys. Res., 116, D06111, doi:10.1029/2010JD015098.

Hood, L. L., B. E. Soukharev, M. Fromm, and J. P. McCormack, 2001: Origin of extreme ozone minima at middle to high 
northern latitudes. J. Geophys. Res., 106, 20925-20940, doi:10.1029/2001JD900093.

Horinouchi, T., F. Sassi, and B. A. Boville, 2000: Synoptic-scale Rossby waves and the geographic distribution of lateral transport routes between the tropics and the extratropics in the lower stratosphere. J. Geophys. Res., 105, 26579-26592, doi:10.1029/2000JD900281.

Isotta, F., O. Martius, M. Sprenger, and C. Schwierz, 2008: Longterm trends of synoptic-scale breaking Rossby waves in the Northern Hemisphere between 1958 and 2001. Int. J. Climatol., 28, 1551-1562, doi:10.1002/joc.1647.

Kiladis, G. N., 1998: Observations of Rossby waves linked to convection over the eastern tropical Pacific. J. Atmos. Sci., 55, 321-339, doi:10.1175/1520-0469(1998)055<0321:OORWLT>2.0.CO;2.

— , and K. M. Weickmann, 1992: Extratropical forcing of tropical Pacific convection during northern winter. Mon. Wea. Rev., 120, 1924-1938, doi:10.1175/1520-0493(1992)120<1924: EFOTPC $>2.0 . \mathrm{CO} ; 2$.

Koch, P., H. Wernli, and H. C. Davies, 2006: An event-based jetstream climatology and typology. Int. J. Climatol., 26, 283-301, doi:10.1002/joc. 1255 .

Konopka, P., and L. L. Pan, 2012: On the mixing-driven formation of the extratropical transition layer (ExTL). J. Geophys. Res., 117, D18301, doi:10.1029/2012JD017876.

Kunz, A., L. L. Pan, P. Konopka, D. E. Kinnison, and S. Tilmes, 2011: Chemical and dynamical discontinuity at the extratropical tropopause based on START08 and WACCM analyses. J. Geophys. Res., 116, D24302, doi:10.1029/2011JD016686.

Lacis, A., D. J. Wuebbles, and J. A. Logan, 1990: Radiative forcing of climate by changes in the vertical distribution of ozone. J. Geophys. Res., 95, 9971-9981, doi:10.1029/ JD095iD07p09971.

Lee, A. M., R. L. Jones, I. Kilbane-Dawe, and J. A. Pyle, 2002: Diagnosing ozone loss in the extratropical lower stratosphere. J. Geophys. Res., 107 (D11), doi:10.1029/2001JD000538.

Lee, S., and H.-K. Kim, 2003: The dynamical relationship between subtropical and eddy-driven jets. J. Atmos. Sci., 60, 1490-1503, doi:10.1175/1520-0469(2003)060<1490:TDRBSA $>2.0 . C O ; 2$.

Li, C., and J. J. Wettstein, 2012: Thermally driven and eddy-driven jet variability in reanalysis. J. Climate, 25,1587-1596, doi:10.1175/ JCLI-D-11-00145.1.

Limbach, S., E. Schömer, and H. Wernli, 2012: Detection, tracking and event localization of jet stream features in 4-D atmospheric data. Geosci. Model Dev., 5, 457-470, doi:10.5194/ gmd-5-457-2012.

Lorenz, D. J., and D. L. Hartmann, 2003: Eddy-zonal flow feedback in the Northern Hemisphere winter. J. Climate, 16, 12121227, doi:10.1175/1520-0442(2003)16<1212:EFFITN >2.0.CO;2.

_ , and E. T. DeWeaver, 2007: Tropopause height and zonal wind response to global warming in the IPCC scenario integrations. J. Geophys. Res., 112, D10119, doi:10.1029/2006JD008087.

Manney, G. L., R. W. Zurek, A. O’Neill, and R. Swinbank, 1994: On the motion of air through the stratospheric polar vortex. J. Atmos. Sci., 51, 2973-2994, doi:10.1175/1520-0469(1994)051<2973: OTMOAT $>2.0 . \mathrm{CO} ; 2$.

- M. L. Santee, L. Froidevaux, J. W. Waters, and R. W. Zurek, 1996: Polar vortex conditions during the 1995-96 Arctic winter: Meteorology and MLS ozone. Geophys. Res. Lett., 23, 3203-3206, doi:10.1029/96GL02453.

, and Coauthors, 2011: Jet characterization in the upper troposphere/lower stratosphere (UTLS): Applications to climatology and transport studies. Atmos. Chem. Phys., 11, 61156137, doi:10.5194/acp-11-6115-2011.
Martius, O., L. M. Polvani, and H. C. Davies, 2009: Blocking precursors to stratospheric sudden warming events. Geophys. Res. Lett., 36, L14806, doi:10.1029/2009GL038776.

— C. Schwierz, and H. C. Davies, 2010: Tropopause-level waveguides. J. Atmos. Sci., 67, 866-879, doi:10.1175/2009JAS2995.1.

Matthews, A. J., and G. N. Kiladis, 1999: Interactions between ENSO, transient circulation, and tropical convection over the Pacific. J. Climate, 12, 3062-3086, doi:10.1175/1520-0442(1999)012<3062: IBETCA $>2.0 . \mathrm{CO} ; 2$.

McIntyre, M. E., 1995: The stratospheric polar vortex and subvortex: Fluid dynamics and midlatitude ozone loss. Philos. Trans. Roy. Soc. London, 352A, 227-240, doi:10.1098/rsta.1995.0066.

McLandress, C., and T. G. Shepherd, 2009: Simulated anthropogenic changes in the Brewer-Dobson circulation, including its extension to high latitudes. J. Climate, 22, 1516-1540, doi:10.1175/ 2008JCLI2679.1.

- J. F. Scinocca, D. A. Plummer, M. Sigmond, A. I. Jonsson, and M. C. Reader, 2011: Separating the dynamical effects of climate change and ozone depletion. Part II: Southern Hemisphere troposphere. J. Climate, 24, 1850-1868, doi:10.1175/2010JCLI3958.1.

Nakamura, H., and A. Shimpo, 2004: Seasonal variations in the Southern Hemisphere storm tracks and jet streams as revealed in a reanalysis dataset. J. Climate, 17, 1828-1844, doi:10.1175/ 1520-0442(2004)017<1828:SVITSH $>2.0$.CO;2.

Ndarana, T., and D. W. Waugh, 2011: A climatology of Rossby wave breaking on the Southern Hemisphere tropopause. J. Atmos. Sci., 68, 798-811, doi:10.1175/2010JAS3460.1.

Nishii, K., H. Nakamura, and Y. J. Orsolini, 2011: Geographical dependence observed in blocking high influence on the stratospheric variability through enhancement and suppression of upward planetary-wave propagation. J. Climate, 24, 6408-6423, doi:10.1175/JCLI-D-10-05021.1.

Orsolini, Y. J., R. B. Stephenson, and F. J. Doblas-Reyes, 1998: Storm track signature in total ozone during Northern Hemisphere winter. Geophys. Res. Lett., 25, 2413-2416, doi:10.1029/ 98GL01852.

Pan, L. L., and Coauthors, 2009: Tropospheric intrusions associated with the secondary tropopause. J. Geophys. Res., 114, D10302, doi:10.1029/2008JD011374.

Park, M., W. J. Randel, A. Gettelman, S. T. Massie, and J. H. Jiang, 2007: Transport above the Asian summer monsoon anticyclone inferred from Aura Microwave Limb Sounder tracers. J. Geophys. Res., 112, D16309, doi:10.1029/2006JD008294.

Peevey, T. R., J. C. Gille, C. E. Randall, and A. Kunz, 2012: Investigation of double tropopause spatial and temporal global variability utilizing High Resolution Dynamics Limb Sounder temperature observations. J. Geophys. Res., 117, D01105, doi:10.1029/2011JD016443.

Polvani, L. M., and R. Saravanan, 2000: The three-dimensional structure of breaking Rossby waves in the polar wintertime stratosphere. J. Atmos. Sci., 57, 3663-3685, doi:10.1175/ 1520-0469(2000)057<3663:TTDSOB >2.0.CO;2.

_ D. W. Waugh, G. J. Correa, and S.-W. Son, 2011: Stratospheric ozone depletion: The main driver of twentieth-century atmospheric circulation changes in the Southern Hemisphere. J. Climate, 24, 795-812, doi:10.1175/2010JCLI3772.1.

Randel, W. J., and I. M. Held, 1991: Phase speed spectra of transient eddy fluxes and critical layer absorption. J. Atmos. Sci., 48, 688697, doi:10.1175/1520-0469(1991)048<0688:PSSOTE $>2.0$. CO;2. , and F. Wu, 2005: Kelvin wave variability near the equatorial tropopause observed in GPS radio occultation measurements. J. Geophys. Res., 110, D03102, doi:10.1029/2004JD005006. 
—, D. J. Seidel, and L. Pan, 2007: Observational characteristics of double tropopauses. J. Geophys. Res., 112, D07309, doi:10.1029/ 2006JD007904.

Rienecker, M. M., and Coauthors, 2008: The GEOS-5 data assimilation system-Documentation of versions 5.0.1, 5.1.0, and 5.2.0. NASA Tech. Rep. TM-2008-104606, 97 pp. [Available online at http://gmao.gsfc.nasa.gov/pubs/docs/Rienecker369.pdf.]

_- and Coauthors, 2011: MERRA: NASA's Modern-Era Retrospective Analysis for Research and Applications. J. Climate, 24, 3624-3648, doi:10.1175/JCLI-D-11-00015.1.

Robinson, W. A., 2006: On the self-maintenance of midlatitude jets. J. Atmos. Sci., 63, 2109-2122, doi:10.1175/JAS3732.1.

Rogal, M., M. H. Hitchman, M. L. Buker, G. J. Tripoli, I. Stajner, and H. Hayashi, 2010: Modeling the effects of Southeast Asian monsoon outflow on subtropical anticyclones and midlatitude ozone over the southern Indian Ocean. J. Geophys. Res., 115, D20101, doi:10.1029/2009JD012979.

Rosenlof, K. H., A. F. Tuck, K. K. Kelly, J. M. Russell III, and M. P. McCormick, 1997: Hemispheric asymmetries in water vapor and inferences about transport in the lower stratosphere. J. Geophys. Res., 102, 13213-13234, doi:10.1029/97JD00873.

Santee, M. L., G. L. Manney, N. J. Livesey, L. Froidevaux, M. J. Schwartz, and W. G. Read, 2011: Trace gas evolution in the lowermost stratosphere from Aura Microwave Limb Sounder measurements. J. Geophys. Res., 116, D18306, doi:10.1029/ 2011JD015590.

Sardeshmukh, P. D., and B. J. Hoskins, 1988: The generation of global rotational flow by steady idealized tropical divergence. J. Atmos. Sci., 45, 1228-1251, doi:10.1175/ 1520-0469(1988)045<1228:TGOGRF $>2.0$. CO; 2 .

Schiemann, R., D. Lüthi, and C. Schar, 2009: Seasonality and interannual variability of the westerly jet in the Tibetan Plateau region. J. Climate, 22, 2940-2957, doi:10.1175/2008JCLI2625.1.

Schoeberl, M. R., 2004: Extratropical stratosphere-troposphere mass exchange. J. Geophys. Res., 109, D13303, doi:10.1029/ 2004JD004525.

_ - L. R. Lait, P. A. Newman, and J. E. Rosenfield, 1992: The structure of the polar vortex. J. Geophys. Res., 97, 7859-7882, doi:10.1029/91JD02168.

Schubert, S., H. Wang, and M. Suarez, 2011: Warm season subseasonal variability and climate extremes in the Northern Hemisphere: The role of stationary Rossby waves. J. Climate, 24, 4773-4792, doi:10.1175/JCLI-D-10-05035.1.

Schwierz, C., S. Dirren, and H. C. Davies, 2004: Forced waves on a zonally aligned jet stream. J. Atmos. Sci., 61, 73-87, doi:10.1175/ 1520-0469(2004)061<0073:FWOAZA > 2.0.CO;2.

Seidel, D. J., Q. Fu, W. J. Randel, and T. J. Reichler, 2008: Widening of the tropical belt in a changing climate. Nat. Geosci., 1, 21-24, doi:10.1038/ngeo.2007.38.

Shepherd, T. G., 2002: Issues in stratosphere-troposphere coupling. J. Meteor. Soc. Japan, 80, 769-792, doi:10.2151/jmsj.80.769.

Sigmond, M., and J. F. Scinocca, 2010: The influence of the basic state on the Northern Hemisphere circulation response to climate change. J. Climate, 23, 1434-1446, doi:10.1175/ 2009JCLI3167.1.
Solomon, S., K. H. Rosenlof, R. W. Portmann, J. S. Daniel, S. M. Davis, T. J. Sanford, and G.-K. Plattner, 2010: Contributions of stratospheric water vapor to decadal changes in the rate of global warming. Science, 327, 1219-1223, doi:10.1126/ science. 1182488 .

Son, S.-W., and S. Lee, 2005: The response of westerly jets to thermal driving in a primitive equation model. J. Atmos. Sci., 62, 3741-3757, doi:10.1175/JAS3571.1.

- and Coauthors, 2008: The impact of stratospheric ozone recovery on the Southern Hemisphere westerly jet. Science, 320, 1486-1489, doi:10.1126/science.1155939.

Sprenger, M., M. C. Maspoli, and H. Wernli, 2003: Tropopause folds and cross-tropopause exchange: A global investigation based upon ECMWF analyses for the time period March 2000 to February 2001. J. Geophys. Res., 108, 8518, doi:10.1029/ 2002JD002587.

Strong, C., and R. E. Davis, 2007: Winter jet stream trends over the Northern Hemisphere. Quart. J. Roy. Meteor. Soc., 133, 21092115, doi:10.1002/qj.171.

— , and - 2008: Variability in the position and strength of winter jet stream cores related to Northern Hemisphere teleconnections. J. Climate, 21, 584-592, doi:10.1175/2007JCLI1723.1.

Wallace, J. M., G.-H. Lim, and M. L. Blackmon, 1988: Relationship between cyclone tracks, anticyclone tracks and baroclinic waveguides. J. Atmos. Sci., 45, 439-462, doi:10.1175/1520-0469 (1988) $045<0439:$ RBCTAT $>2.0 . C O ; 2$

Waugh, D. W., and D. G. Dritschel, 1999: The dependence of Rossby wave breaking on the vertical structure of the polar vortex. J. Atmos. Sci., 56, 2359-2375, doi:10.1175/ 1520-0469(1999)056<2359:TDORWB >2.0.CO;2.

_ , and W. J. Randel, 1999: Climatology of Arctic and Antarctic polar vortices using elliptical diagnostics. J. Atmos. Sci., 56, 1594-1613, doi:10.1175/1520-0469(1999)056<1594:COAAAP $>2.0 . C O ; 2$.

— , and L. M. Polvani, 2000: Climatology of intrusions into the tropical upper troposphere. Geophys. Res. Lett., 27, 38573860, doi:10.1029/2000GL012250.

Wilcox, L. J., B. J. Hoskins, and K. P. Shine, 2012: A global blended tropopause based on ERA data. Part I: Climatology. Quart. J. Roy. Meteor. Soc., 138, 561-575, doi:10.1002/qj.951.

Williams, L. N., S. Lee, and S.-W. Son, 2007: Dynamics of the Southern Hemisphere spiral jet. J. Atmos. Sci., 64, 548-563, doi:10.1175/JAS3939.1.

Woollings, T., A. Hannachi, and B. Hoskins, 2010: Variability of the North Atlantic eddy-driven jet stream. Quart. J. Roy. Meteor. Soc., 136, 856-868, doi:10.1002/qj.625.

, J. G. Pinto, and J. A. Santos, 2011: Dynamical evolution of North Atlantic ridges and poleward jet stream displacements. J. Atmos. Sci., 68, 954-963, doi:10.1175/2011JAS3661.1.

Wu, W.-S., R. J. Purser, and D. F. Parish, 2002: Three-dimensional variational analyses with spatially inhomogeneous covariances. Mon. Wea. Rev., 130, 2905-2916, doi:10.1175/ 1520-0493(2002) $130<2905$ :TDVAWS $>2.0$.CO 2 .

Zängl, G., and K. P. Hoinka, 2001: The tropopause in the polar regions. J. Climate, 14, 3117-3139, doi:10.1175/ 1520-0442(2001)014<3117:TTITPR >2.0.CO;2. 